Article

\title{
Ramjet Compression System for a Hypersonic Air Transportation Vehicle Combined Cycle Engine
}

\author{
Sasha Veeran ${ }^{1}$, Apostolos Pesyridis ${ }^{1,2, *}$ (i) and Lionel Ganippa ${ }^{1}$ \\ 1 Centre of Advanced Powertrain and Fuels (CAPF), Department of Mechanical, Aerospace and Civil \\ Engineering, Brunel University London, Middlesex UB8 3PH, UK; 1212468@brunel.ac.uk (S.V.); \\ Lionel.Ganippa@brunel.ac.uk (L.G.) \\ 2 Metapulsion Engineering Ltd., Northwood, Middlesex HA6 3LG, UK \\ * Correspondence: a.pesyridis@brunel.ac.uk
}

Received: 9 July 2018; Accepted: 21 September 2018; Published: 25 September 2018

\begin{abstract}
This report assesses the performance characteristics of a ramjet compression system in the application of a hypersonic vehicle. The vehicle is required to be self-powered and perform a complete flight profile using a combination of turbojet, ramjet and scramjet propulsion systems. The ramjet has been designed to operate between Mach 2.5 to Mach 5 conditions, allowing for start-up of the scramjet engine. Multiple designs, including varying ramp configurations and turbo-ramjet combinations, were investigated to evaluate their merits and limitations. Challenges arose with attempting to maintain sufficient pressure recoveries and favourable flow characteristics into the ramjet combustor. The results provide an engine inlet design capable of propelling the vehicle between the turbojet and scramjet phase of flight, allowing for the completion of its mission profile. Compromises in the design, however, had to be made in order to allow for optimisation of other propulsion systems including the scramjet nozzle and aerodynamics of the vehicle; it was concluded that these compromises were justified as the vehicle uses the ramjet engine for a minority of the flight profile as it transitions between low supersonic to hypersonic conditions.
\end{abstract}

Keywords: ramjet; scramjet; hypersonic; combustion; hypersonic engine integration; combined cycle engine; CFD

\section{Introduction}

Following the discovery of flight in 1903, the Wright brothers sparked a challenge that would keep engineers busy for decades to come. The challenges included methods of propulsion, aircraft aerodynamic design, aircraft structural design and control methods. Although many of these issues have been solved for both subsonic and supersonic flight, the hypersonic flight profile is still a relatively new concept, bringing a variety of challenging issues along with it. Thermal loading is a major issue for aircraft flying at high Mach numbers caused by the skin friction between the air and vehicle body.

Another issue that requires careful attention is the aerodynamic design of the aircraft and its wings; the aircraft must take into consideration the shock waves formed, while the wing design must be able to achieve sufficient lift at low speed and low altitude conditions, as well as at high speed and high altitude conditions.

The National Aeronautics and Space Administration's (NASA's) X-15 is a hypersonic rocket powered aircraft which managed to achieve Mach 6.72 with its first flight in June 1959. A more recent variant, the X-43a, increased this limit to Mach 9.65 with the accomplishment of using an air breathing scramjet engine [1]. With commercial airline travel averaging flight speeds between Mach 0.82 to 0.86 , transatlantic flights such as New York to London can take more than seven hours. Although Concorde 
temporarily reduced this flight time to $3.5 \mathrm{~h}$, its luxury remains only a memory due to its retirement in 2003 - a result of rising fuel and maintenance costs.

The goal of hypersonic flight is an appealing thought for most of the population, including those with business needs, personal travel and emergency situations such as medical evacuation. The challenges faced by commercial hypersonic flight consist of several aspects ranging from formation of sonic booms (which are banned over most land masses) along with dealing with the more technical aspects such as thermal management of the wetted surfaces and propulsion systems. From the experimental flights of the $\mathrm{X}-43 \mathrm{a}$, it was established that surface temperatures rapidly increased to $950^{\circ} \mathrm{C}$ [2], let alone the thermal predictions for such a hypersonic vehicle which reach $1370{ }^{\circ} \mathrm{C}$ at Mach 12 flight-well beyond the thermal limitations of most commonly used aerospace materials.

Since a hypersonic aircraft operates at subsonic $(M<1)$, supersonic $(1<M<5)$ and hypersonic $(M>5)$ flight conditions, its drag characteristics will vary drastically throughout the different regimes. Subsonic flight experiences a significant component of drag from lift induced drag, whereas supersonic and hypersonic flight experiences mainly base and wave drag [3]. Base drag is the partial vacuum formed aft of the aircraft as the vehicle passes through the air, and wave drag is a result of the formation of shock waves. Base and wave drag are directly influenced by the volume and cross-sectional area of the vehicle, so it is imperative that these are kept to a minimum [4]. With regards to commercial hypersonic flight, there will need to be a compromise made between payload and aerodynamic design which will determine the operational efficiency and feasibility for an airline [5].

The aircraft design will need to take into consideration the method of lift generation when flying at hypersonic speeds; more specifically, some designs utilise the aerodynamic forces generated on the aircraft underbody to assist in providing lift at high altitudes where the air density is significantly lower than at sea level. The SR-71 was an aircraft using this technique to assist in lift generation, flying with $\mathrm{a}+3^{\circ}$ attitude at supersonic speed to help increase the coefficient of lift $(\mathrm{CL})$, reducing the need for increased wing size in an effort to maintain an aerodynamic profile.

To achieve hypersonic velocity, combined-cycled engines of varying configurations have been proposed over the years and this paper proposes once such cycle focussing on the intermediate (ramjet) stage to propel the concept aircraft proposed up to Mach 5 before the hypersonic (scramjet) stage kicks-in.

\section{Ramjet Engines and Concept Aircraft Specification}

The ramjet is a method of propulsion that relies on its geometry to accomplish the compression and expansion phases needed to produce thrust. Current designs experience greatest efficiencies near Mach 3, with a top speed of around Mach 6; far greater than that of a typical turbojet which would experience considerable structural damage at speeds greater than Mach 2.2 due to the formation of shock waves and immense thermal loading.

A ramjet does not require the compressor stages as it uses the aircraft's forward speed to compress the air as it enters the inlet; this implies that the ramjet will be inoperable at velocities insufficient for adequate compression i.e., less than Mach 2-bringing to light its main drawback, its inability to produce static thrust.

At sufficient free stream velocities, the oncoming flow enters the engine and the pressure increases-this is due to the formation of shock waves within the engine inlet because of the supersonic speeds. It is important to control the shock wave formation, with the goal being to maintain a normal shock wave throughout the flight regime and possible changes in the angle of attack-this manipulation of the shock wave location is dealt with by the inlet inner-body, sometimes referred to as the inlet spike or centre body. There are alternative designs utilising a rectangular inlet with multiple ramps to achieve similar effects as the inlet spike.

The hypersonic transport vehicle designed had to meet the following performance specifications:

1. The aircraft must accommodate at least 100 passengers;

2. It must be capable of taking off and landing onto current airports and runways; 
3. Capable of cruising at an altitude of $30 \mathrm{~km}(100,000 \mathrm{ft})$ and at a speed of Mach 8; and

4. Must have a range of more than $12,000 \mathrm{~km}$.

An example outline of the desired profile is given in Table 1 [6]. In order to remain feasible, the profile is attained by the combined operation of a turbojet, ramjet, and scramjet propulsion system.

A feasible combination of a dual-mode ramjet-scramjet is given in Figure 1, such that during high-altitude scramjet flight, the ramjet inlets are sealed to prevent excessive drag induced by shockwaves on the ramjet forebody.

Table 1. Concept aircraft target flight profile.

\begin{tabular}{|c|c|c|c|c|c|c|}
\hline Phase & Description & Altitude (ft) & Mach & Turbojet & Ramjet & Scramjet \\
\hline 1 & $\begin{array}{l}\text { Take-off and } \\
\text { initial climb }\end{array}$ & 0-1500 & 0 to 1 & & & \\
\hline 2 & Climb 1 & $1500-40,000$ & 1 to 2 & & & \\
\hline 3 & Climb 2 & $40,000-60,000$ & 2 to 4 & & & \\
\hline 4 & Climb 3 & $60,000-100,000$ & 4 to 7 & & & \\
\hline \multirow[t]{2}{*}{5} & Cruise & 100,000 & 8 & & & \\
\hline & Single Operation & & Dual Operation & & $\mathrm{NoO}$ & ration \\
\hline
\end{tabular}

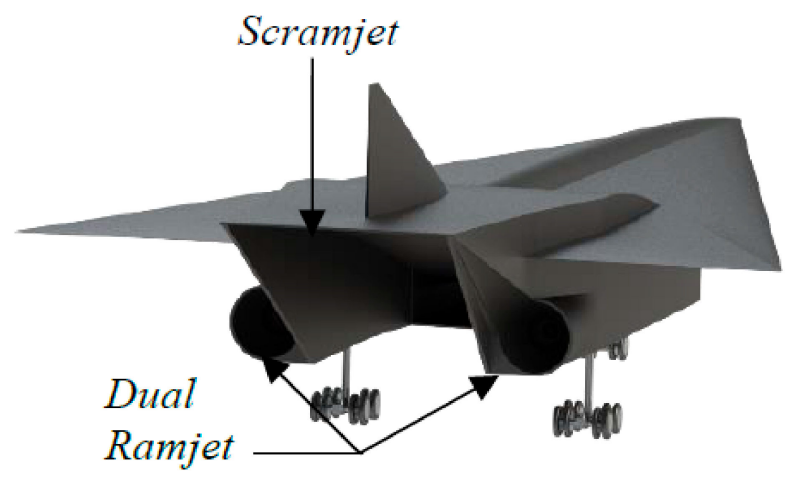

Figure 1. Concept hypersonic aircraft.

The requirement from this aircraft was for sustained Mach 8 cruise flight for a substantial part of the flight envelope with the ramjets assisting during Phases 2 and 3 of the flight envelope (Table 1). The concept aircraft, as well as its combustion characteristics, have been detailed in previous publications [6-8].

\section{Ramjet Design and Optimisation}

\subsection{Numerical Analysis and Validation}

The first aspect to consider is the physical inlet area, which will need to provide the required mass of air into the engine at all operating conditions. The mass of air required is determined by the amount of thrust needed to propel the vehicle from the region where the turbojet engines lose effectiveness (Mach 2.5), to the starting point of the scramjet envelope (circa Mach 4.5).

The flight Mach number, altitude and aircraft angle of attack will all influence the design and performance of the ramjet and must be taken into consideration. The following schematics show the numerical results of using different inlet configurations (i.e., ramp angle and configurations) at different Mach numbers. These calculations are used to ensure that the subsequent CFD results (conducted in ANSYS Fluent using ANSYS Workbench 17) obtain similar results regarding Mach number and flow properties across the different oblique and normal shock waves.

In addition to the validation achieved via numerical analysis, it was decided to use a verified ramjet inlet CFD setup presented by the Californian Naval Postgraduate School. This comparison 
further confirmed the reliability of the results and ensured that the appropriate mesh and boundary conditions were used.

The test conditions were set at Mach 4 with a static pressure at the inlet of $7378 \mathrm{~Pa}$. A comparison of the verified CFD results are shown in Figure 2b [9], which can be seen to satisfactorily resemble the CFD results obtained within this paper (Figure 2a). The flow conditions and geometries were identical and the results (comparing profiles and velocity values) were within a $5 \%$ range, which was considered acceptable.

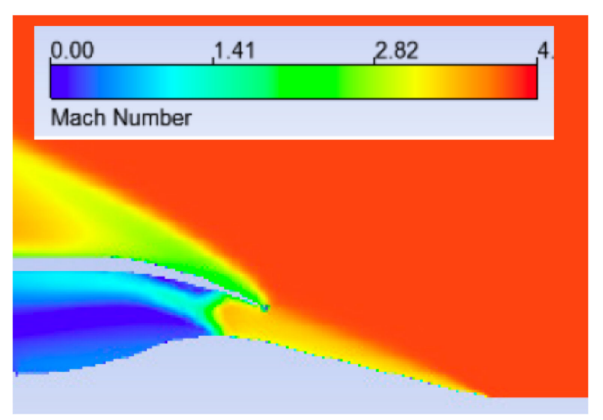

(a)

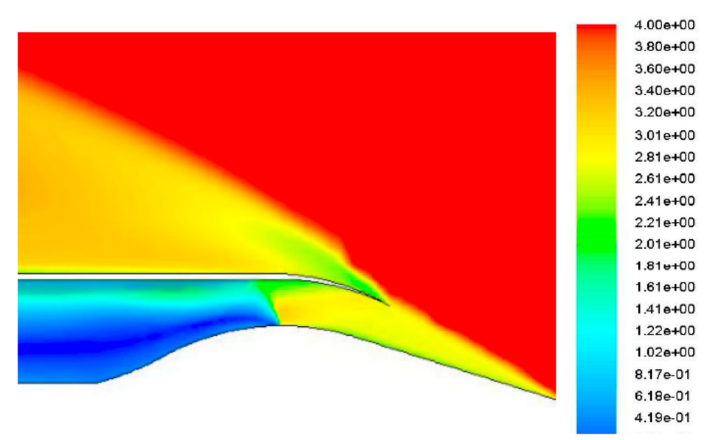

(b)

Figure 2. Validation comparison (a) verified CFD and (b) this paper's CFD.

There is a slight variation in the location of the terminal shock in the results achieved in this report. Here, the normal shock has been pushed rearward slightly, as a result of the difference in mesh density. However, as the results are very similar, it can be inferred that the CFD setup used within this report is representative for the current flight conditions and will yield reliable results.

For inlets operating at high Mach numbers, it is desirable to maintain a straight cowl lip. Alternative designs include slightly curved cowl lips to help manipulate the flow direction of the air, however as the Mach numbers increase, the curved cowl lip reduces the efficiency of the inlet.

\subsection{CFD Setup}

To obtain reliable CFD results, it is crucial that the correct boundary conditions, models and solvers are being used at the appropriate conditions. With the ramjet operating at supersonic flight conditions, it is crucial that this is accurately reflected in the setup of the problem.

The boundary conditions were set as follows: the ramjet structure was defined as 'wall', allowing for the no-slip condition, and the surrounding fluid domain was defined as 'pressure far-field' to enable the input of surrounding static pressure, temperature, turbulence and Mach number [10].

The chosen solver type was 'density based' due to the high Mach number and compressible nature of the flow; the numerical solution methods were set as 'implicit' and 'second order' due to the need for coupled equations (pressure and density). The simulation was run under transient conditions with a time step of $0.01 \mathrm{~s}$, for 500 time steps, with 20 iterations per time step. This resulted in a total simulation time of $5 \mathrm{~s}$, allowing for convergence of the simulation and stabilisation of the flow. Further details of the mesh and the sensitivity study conducted are provided in Appendix A.

\subsubsection{Configuration 1-Mach 2.5 Analysis}

Figure 3 shows two configurations for the ramjet inlet; in Configuration A, the shock has been pushed back into the diverging section of the inlet. This allows for stability of the shock but does not produce efficient pressure recovery. For optimum pressure recovery (pressure rise in the intake due to flow deceleration), the shock should be nearer the inlet throat as in Configuration B.

The spillage drag presented above (Figure 2) is minimal and is a result of the most forward ramp creating a shock that is not aligned with the cowl lip. The main reason for this is that the aircraft will spend very little time flying at Mach 2.5. The inlet must be designed to accommodate flow conditions 
at Mach numbers of 2.5 to 5, meaning that compromises will need to be made. When the vehicle Mach number increases, so does the drag-therefore, it is more effective to compromise efficiency at lower Mach numbers where drag is relatively low to allow for optimisation of the inlet design for higher Mach numbers.

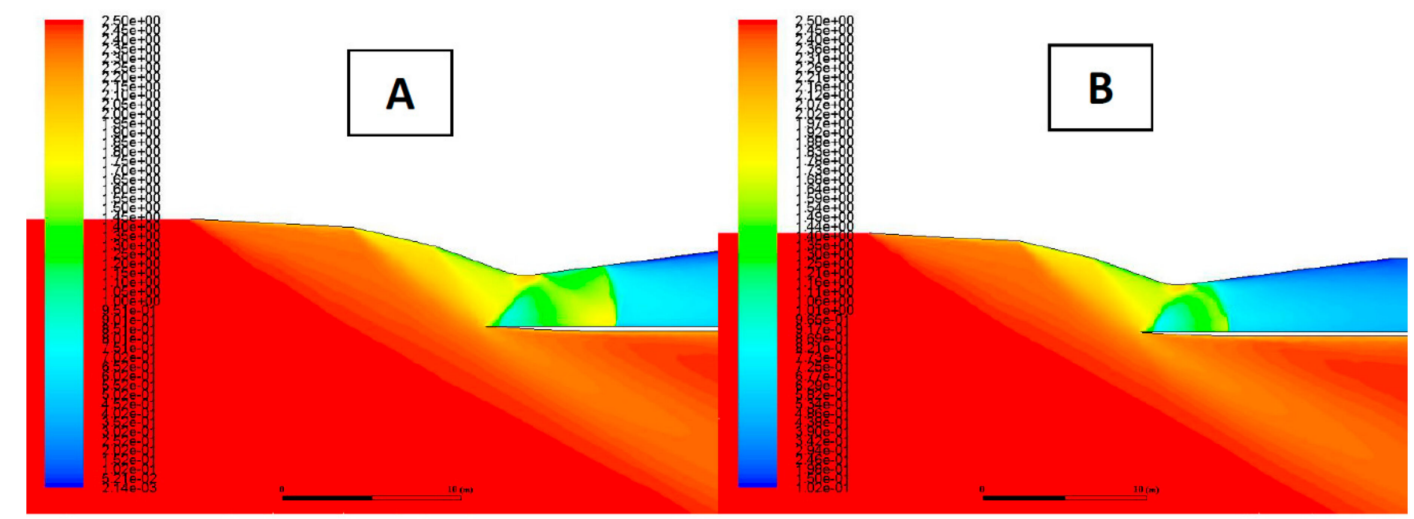

Figure 3. Mach number contours for the optimised inlet for Mach 2.5. for configurations (A,B).

As the Mach number increases, the shock angles will reduce, allowing for better alignment of the shock waves with the cowl lip. Although the aircraft will not cruise at any conditions where the ramjet is the main source of thrust, it is important to maintain an efficient design to achieve the best aerodynamic performance.

For lower Mach numbers such as Mach 2.5, the use of three inlet ramps may seem excessive, however to achieve maximum pressure recovery at higher Mach numbers, more oblique shocks are required. There is a possibility to implement a variable geometry inlet into the design, allowing for a more ideal configuration at each Mach number, however this has obvious downsides including added weight, maintenance and it must be robust enough to withstand the aero-loading at Mach 8 when the vehicle is being propelled by the scramjet. Such phenomena may, in the first instance, be studied using simplified numerical tools [11]. Other phenomena of importance include the possible effects that thermochemical non-equilibrium has on the shock location and therefore on the performance of the inlet compression system, which were outside of the scope of this work [12].

Using the three-ramp configuration covered extensively in [6], Figure 4 shows that at Mach 2.5, the inlet total pressure loss is $23 \%$. This is quite a substantial pressure loss and is a result of losses within the shock waves, frictional and boundary layer effects.

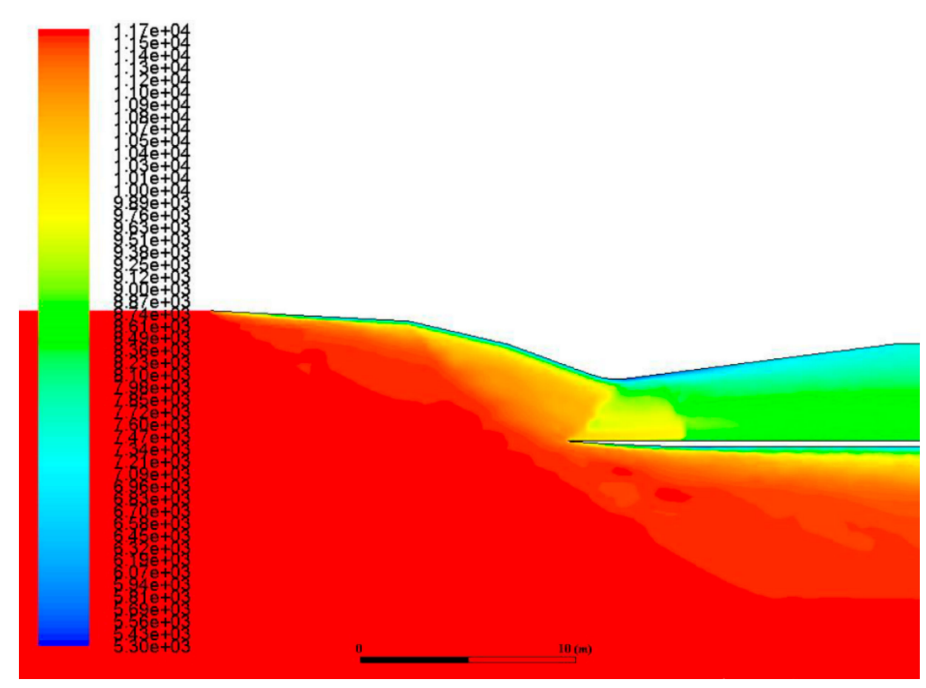

Figure 4. Mach 2.5 total pressure (Pa). 
Figure 5 shows the increase in static pressure as the flow enters the inlet. This compression is necessary for the proper combustion and thrust production of the ramjet engine. In a jet engine, the compressor is responsible for compressing the flow to the required pressures, where the flow is then ignited and ejected. The ramjet relies on the vehicle forebody and ramps to provide adequate compression at a given Mach number.

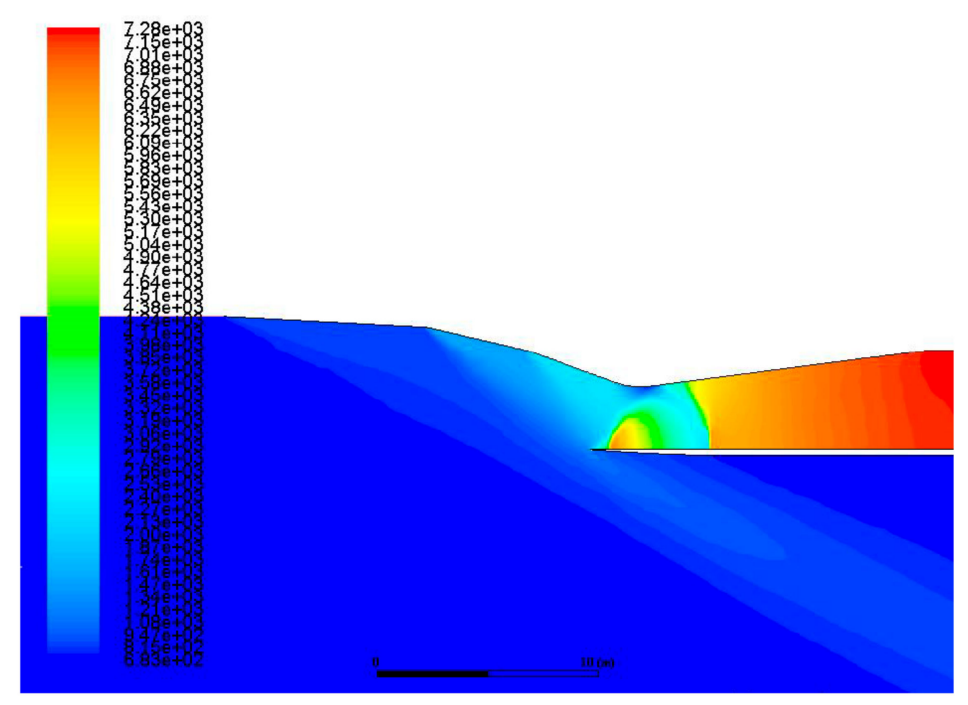

Figure 5. Mach 2.5 static pressure (Pa).

The rapid compression and deceleration of the flow causes the static temperature of the flow to increase (changing kinetic energy to thermal energy) as it progresses into the inlet, as shown in Figure 5. This is important as most ramjet designs rely on the flow combusting due to the fuel flash point being reached. This reduces the need for spark systems, but requires reliable control of the static temperatures within the inlet. Future designs are targeting laser ignition systems in an effort to burn fuel more effectively with reduced emissions [13].

\subsubsection{Configuration 2-Mach 3.0 Analysis}

As the Mach number increases, the shock waves begin to fall on the cowl lip, allowing for better inlet performance; the important aspect being that the normal shock is still located just aft of the inlet throat (Figure 6). At this Mach number, the shock waves are reflecting within the inlet and terminate with a normal shock. This is expected and helps to gradually decelerate the flow.

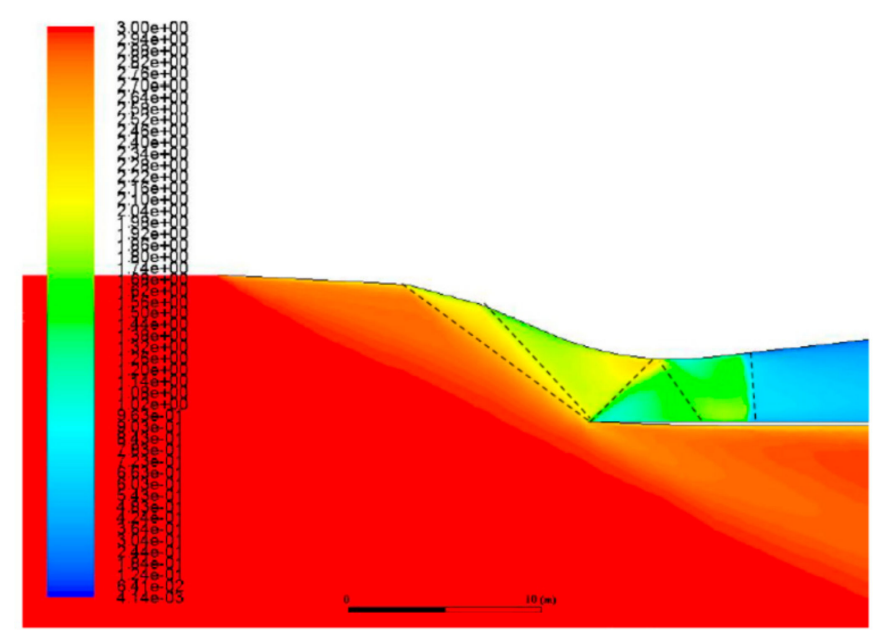

Figure 6. Mach 3.0 Mach contour. 


\subsubsection{Configuration 3-Mach 5.0 Analysis}

As the Mach number increases, the shock waves begin to fall on the cowl lip, allowing for better inlet performance; the important aspect being that the normal shock is still located just aft of the inlet throat (Figure 7). At this Mach number, the shock waves are reflecting within the inlet and terminate with a normal shock. This is expected and helps to gradually decelerate the flow.

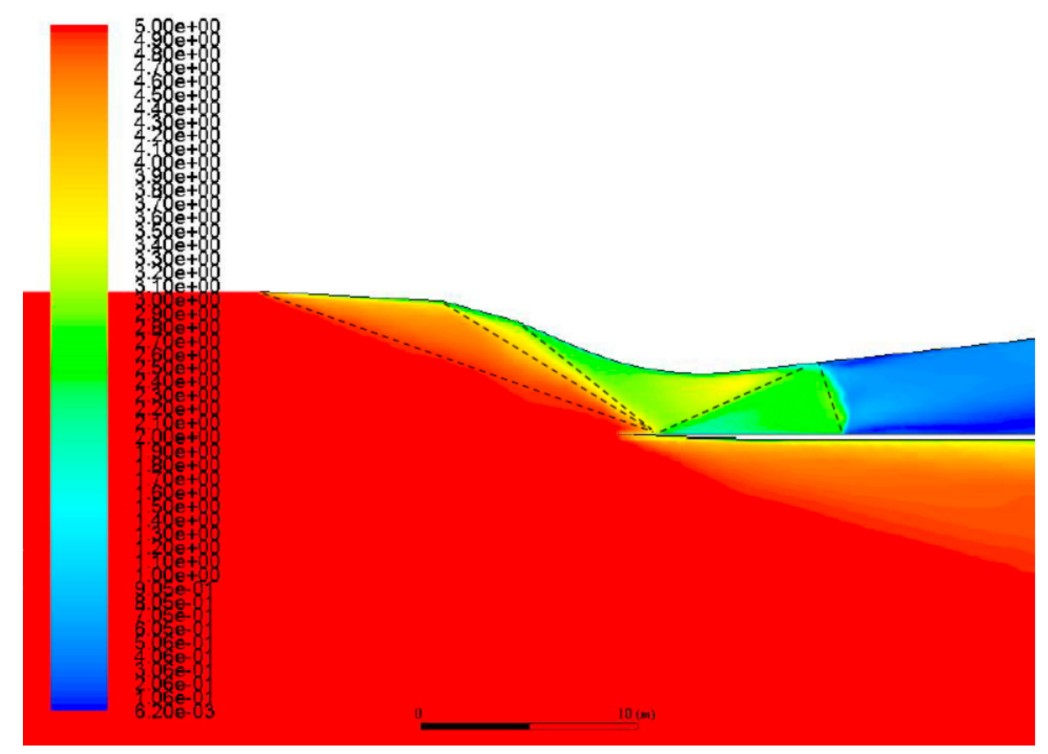

Figure 7. Mach 5.0 Mach contour.

Configuration 3, a three-ramp inlet design, is seen to reduce the flow down to suitable Mach numbers at varying free stream conditions. Besides the requirement of providing airflow at the correct Mach number, sufficient static pressure ratios and total pressure recoveries must be achieved. Figure 8 shows that as the Mach number increases, so does the compression ratio. At Mach 2.5, there is a compression ratio of just over 10, whereas at Mach 5, the pressure ratio reaches just below 60 .

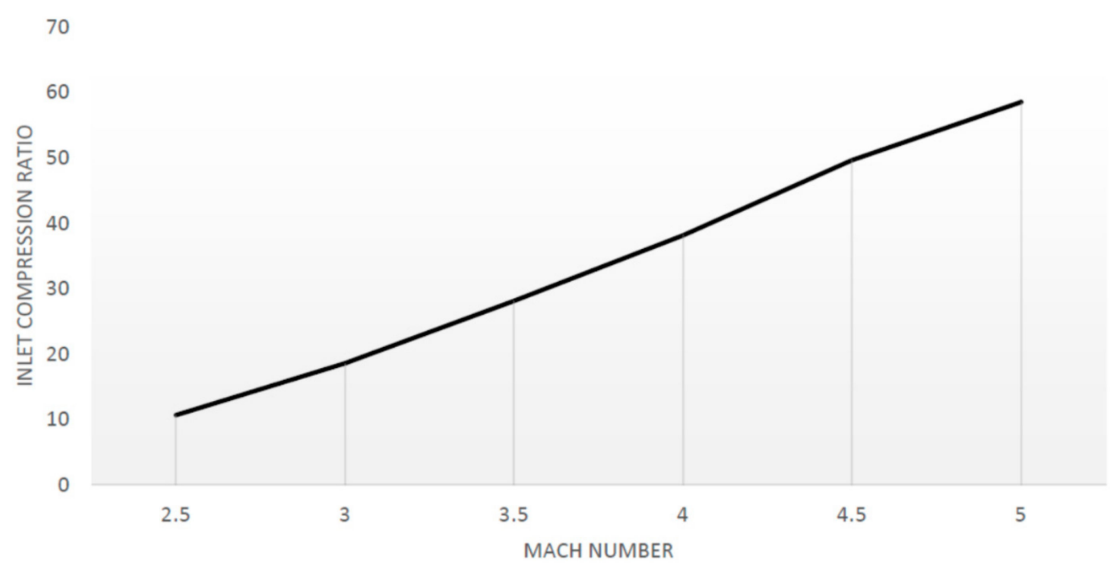

Figure 8. Inlet compression ratio vs. Mach number.

The pressure recovery reduces as the Mach number increases, a penalty for reducing the flow from higher Mach numbers to subsonic conditions. The results obtained in Figure 9 correspond with the three-ramp configuration shown in the above CFD schematics in Sections 3.2 and 3.2. The pressure recoveries are consistently lower than those presented by the 'normal shock +3 oblique shock' configuration shown, found in the literature [14]. At Mach 2.5, there is a difference in pressure recovery of $13 \%$; this increases to a difference of $20 \%$ at Mach 4 . 


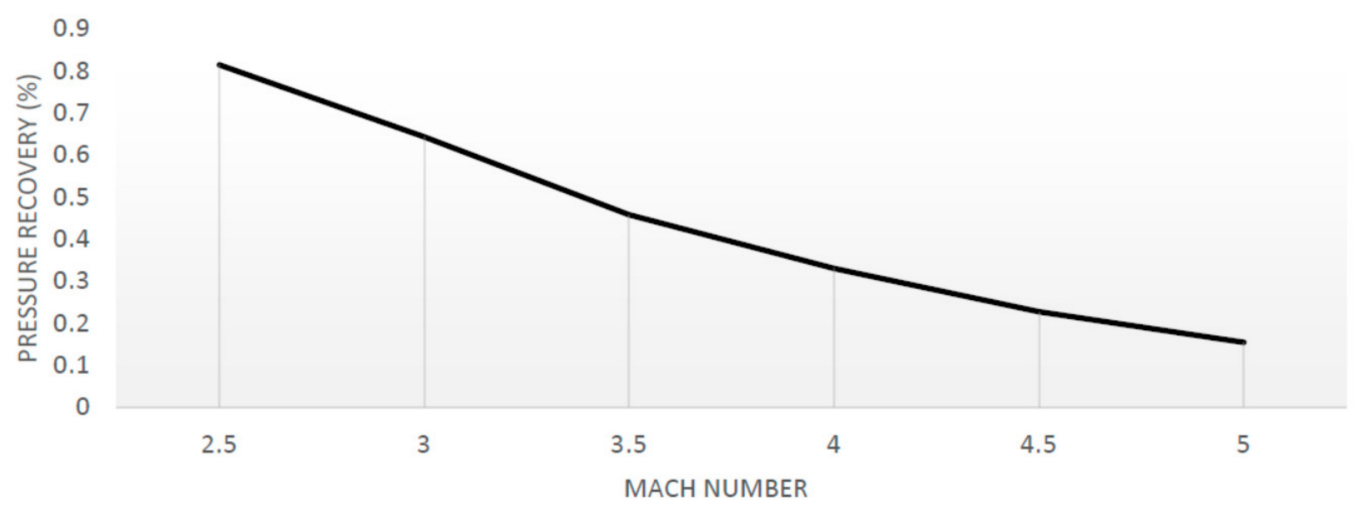

Figure 9. Pressure recovery vs. Mach number.

As this ramjet will only be operational for a relatively small aspect of the flight profile, it is important to ensure that its design will not greatly affect the aerodynamics of the hypersonic vehicle when in its cruise phase. As a result, shallower ramp angles were chosen to help preserve a slender aerodynamic shape for when the ramjet is not in use.

\subsection{Angle of Attack Considerations}

With a change in angle of attack (AoA), the airflow into the inlet will experience greater changes in direction in comparison to the aircraft flying level. There is a need to ensure that the shock waves will reliably decelerate the flow while maintaining sufficient airflow into the inlet and not creating additional spillage drag.

Since the ramjet is used to accelerate the vehicle to the region of Mach 2.5 to 5 and increase the altitude from $50,000 \mathrm{ft}$ to roughly $80,000 \mathrm{feet}$, for most of the ramjet flight profile, it will experience positive angles of attack. Furthermore, the air density will decrease as the vehicle gains altitude, bringing many advantages and disadvantages. The reducing air density will reduce the air resistance experienced by the entire vehicle, however, it will also reduce the mass flow rate into the inlet of the ramjet. As the aircraft approaches the engine switch over speed (to the scramjet), there will be a phase where both the ramjet and scramjet will be simultaneously producing thrust for the vehicle. This will help to create additional thrust to counter the high levels of drag experienced as the vehicle enters the hypersonic flight regime. Once the scramjet engine has successfully started, the vehicle will continue to accelerate up until the ramjet no longer becomes advantageous (circa Mach 5).

In Figure 10 below, we can see a comparison between the inlet performing at Mach 3 at an angle of attack of $0^{\circ}$ and $3^{\circ}$.

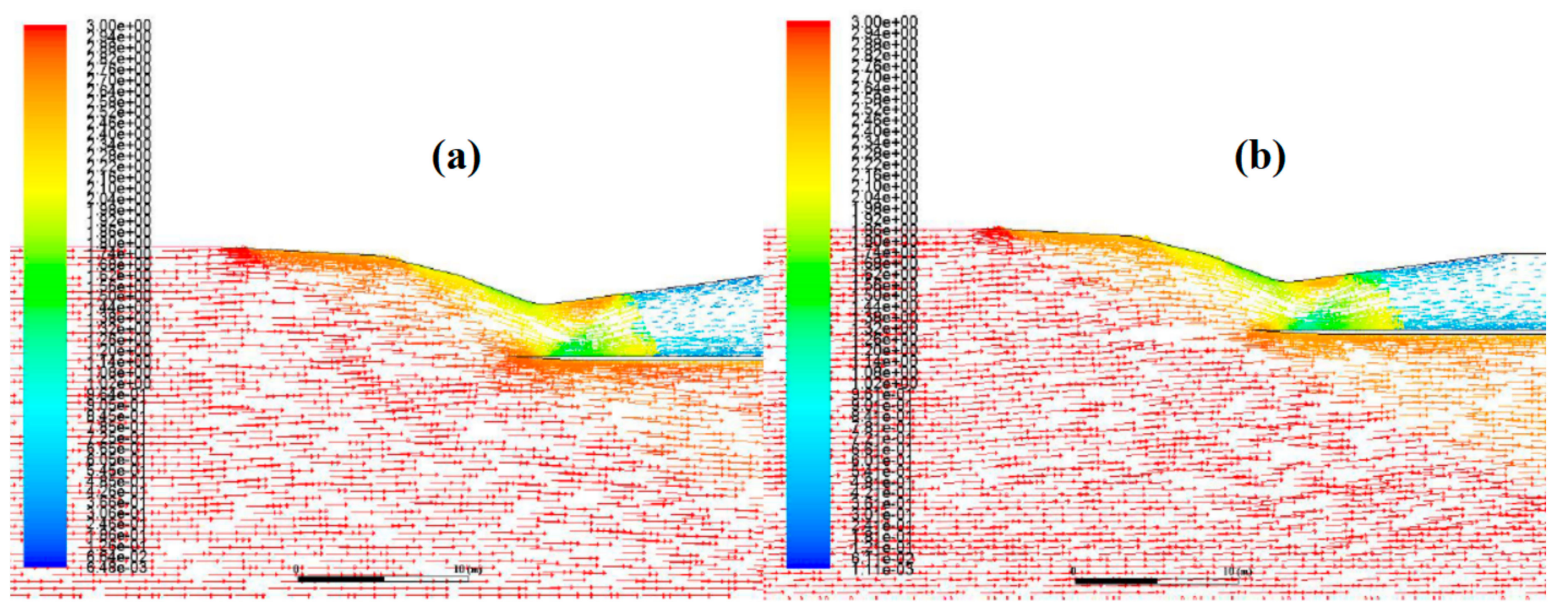

Figure 10. (a) Mach 3, angle of attack (AoA) of $0^{\circ}$ and (b) Mach 3 , AoA of $3^{\circ}$. 
Figure $10 \mathrm{~b}$ shows that when the airflow approaches the aircraft at $3^{\circ}$, the shock formation does not differ greatly when compared to the $0^{\circ}$ configuration (Figure 10a). This is a positive result, as it shows that this design is not easily affected by changing flow direction. Changing flow direction can often cause the normal shock within the inlet to become unstable and be ejected out the front of the inlet, causing unstart conditions. In this case, we can see that the normal shock remains within the divergent section of the inlet and manages to maintain steady airflow into the combustor.

A second test like the one above was performed for Mach 5, again with an AoA of $0^{\circ}$ and $3^{\circ}$ (Figure 11).

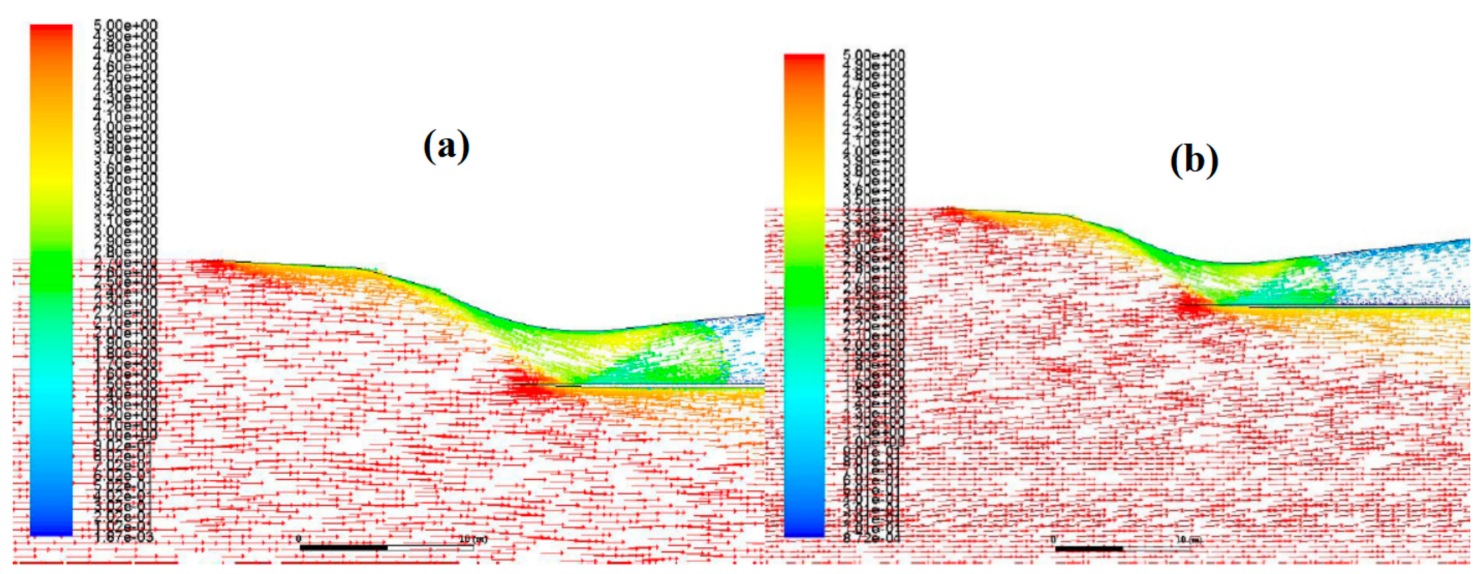

Figure 11. (a) Mach 5, AoA of $0^{\circ}$ and (b) Mach 5, AoA of $3^{\circ}$.

The main difference between the two angles of attack (Figure 11a,b) are that for a $3^{\circ}$ AoA, the shock waves have a slightly shallower angle which can be explained by the change in airflow direction. The normal shock remains within the diverging section of the inlet and can maintain stability, however, it can be seen to have moved forward slightly in the case of a $3^{\circ}$ AoA.

\subsection{Boundary Layer Bleed}

An issue affecting engine inlets is the inevitable presence of an adverse pressure gradient, a result of the increasing static pressure in the direction of the flow. The effect of this is likely to induce additional turbulence within the inlet, boundary layer separation causing poor normal shock stability and ultimately reduced efficiency, and poor performance of the inlet. In order to minimise the effects of the adverse pressure gradient, a series of boundary layer bleed holes can be implemented to help avoid separation from adverse shock waves and boundary layer interactions [15].

Figure 12 shows the two boundary layer test setups used to evaluate the influence that bleed holes have on the boundary layer. Reducing the boundary layer thickness, especially in supersonic inlets, is an important aspect that needs to be taken into consideration. Configuration A is the normal, non-bleed setup and Configuration B is the setup containing a basic bleed system. The bleed hole angles have been set up at an angle of $50^{\circ}$ as recommended by the NASA report 'On Supersonic-Inlet Boundary Layer Bleed Flow' [16], allowing for an optimal boundary layer capture geometry.

A noticeable aspect in Figure 12 is the slight disturbance in the flow just above the bleed system in Configuration B. This indicates that the bleed system has not yet been fully optimised for this configuration. On the other hand, there is a noticeable reduction in the thickness of the boundary layer in Configuration B.

The two images in Figure 13 are taken from the corresponding black boxes indicated in Figure 12. There is a clear reduction in the boundary layer height, with the non-bleed configuration (Configuration A) having a height of $4.12 \mathrm{~mm}$ above the wall at Mach 2.5 and the bleed configuration (Configuration B) having a height of $1.67 \mathrm{~mm}$. This is a reduction in boundary layer height 
of $59 \%$, which is useful when attempting to reduce the potential for separation and boundary layer-shock interference.

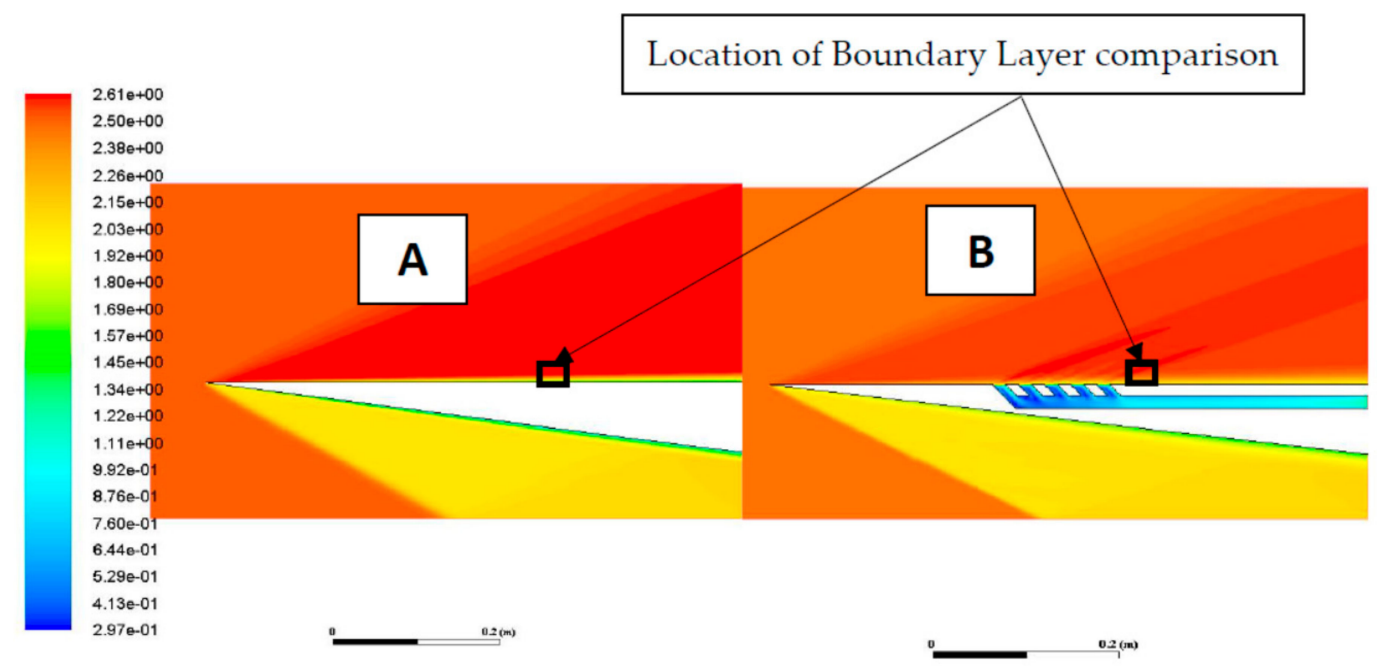

Figure 12. No boundary layer bleed vs. boundary layer bleed for configurations (A,B).

Another noticeable feature is the reduction in size of the viscous sublayer, which is a small component of the boundary layer found directly above the walls. In Figure 13, the viscous sublayer can be visualised by the dark blue region. In this layer, the flow is dominated by shear forces which induce a lot of skin friction drag; reducing this layer will inevitably help with the reduction of drag experienced by the surface. Additionally, a visualisation of the boundary layer profile has been superimposed over the CFD Mach contours to better illustrate the difference in boundary layer height which incurs adverse effects on the flow characteristics.

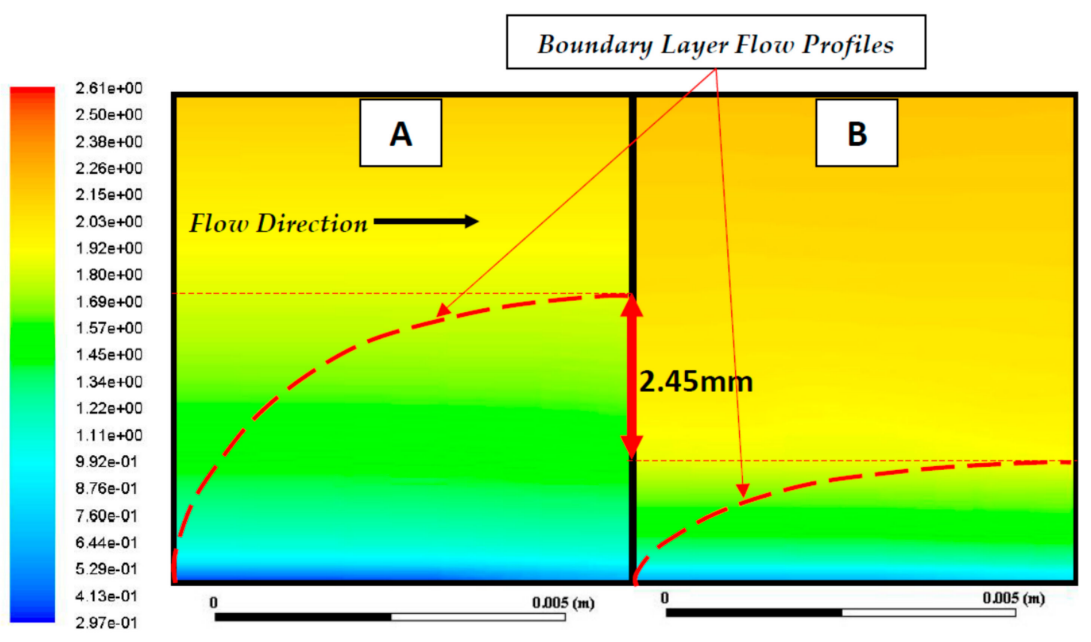

Figure 13. Boundary layer comparison (no bleed vs bleed; configuration (A,B)).

\subsection{Three-Dimensional (3D) CFD Analysis}

Having established a working two-dimensional (2D) model, the influence of a 3D configuration needed to be explored. As mentioned above, the additional shocks created by the sidewalls of the inlet have the adverse effect of introducing further losses within the system [17].

The ramjet design in the following images has utilised the symmetry tool to lower the computational requirements, and hence is twice the width as depicted.

The shock formation in Figure 14 provides a visualisation of the shock formation within the inlet. In addition to the results obtained in the $2 \mathrm{D}$ case, the $3 \mathrm{D}$ results show the interaction of the ramjet side 
wall of the shock wave propagation. The normal shock can still be seen to have formed aft of the inlet throat, allowing for the required deceleration.

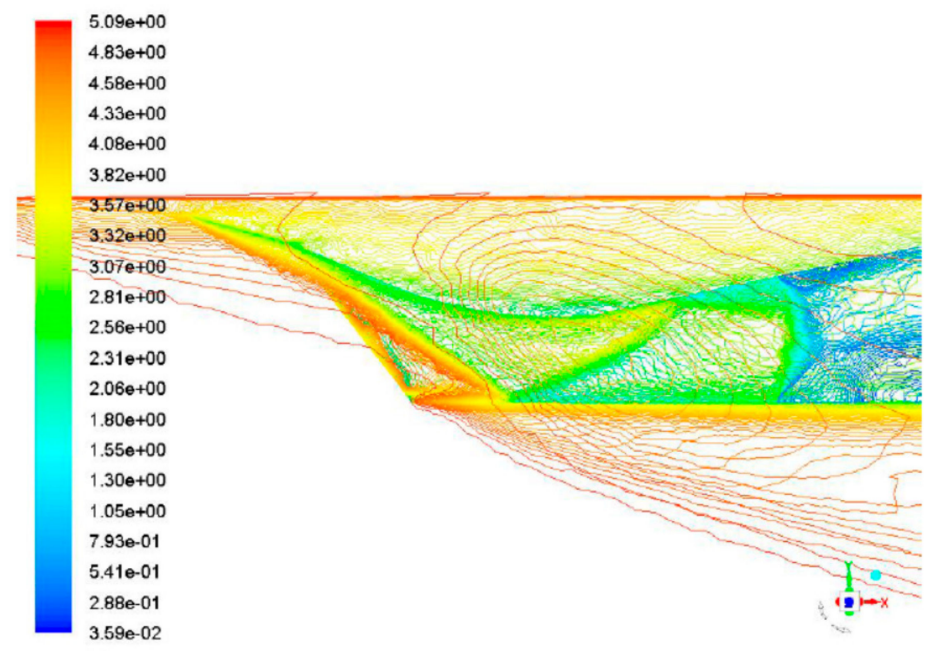

Figure 14. Three-dimensional (3D) shock visualisation.

Figure 15 provides an alternate view where the shock reflection within the inlet and shock propagating from the cowl lip is clearly visible. As the flow enters the combustion chamber, it will be ignited, causing the flow to accelerate out of the nozzle of the engine.

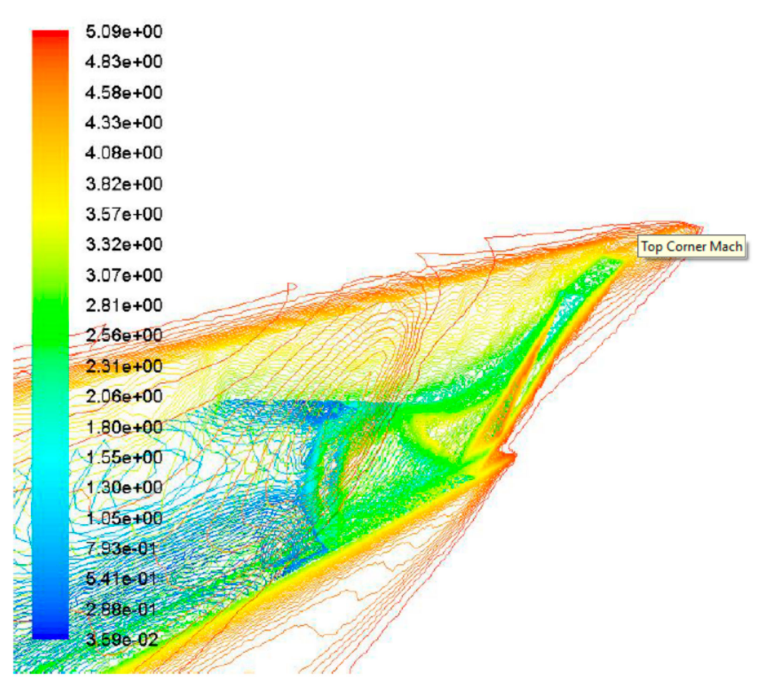

Figure 15. Alternate view of 3D Mach contours.

It is crucial that the combustion chamber pressure remains at a sufficient level to achieve the required thrust. Figure 16a provides the referencing of stations used and Figure 16b shows the static pressure within the ramjet engine at Mach 5 and at 50,000 ft. The increase in static pressure is a result of the increased ramming effect that occurs at higher Mach numbers. Greater compression ratios are required at higher Mach numbers as it contributes to thrust production; there is a trade-off, however, because the propulsive thrust from an engine can be quantified by the ratio between the temperature of the charge entering the combustor and the temperature after combustion. With an increase in the static pressure ratio, there will be an inherent increase in the temperature ratio $\left(T_{2} / T_{0}\right)$. This increase in temperature ratio means that the charge will gain less energy from the fuel as it is being burnt. Ideally, it is desirable for the fuel to transfer as much energy to the flow as possible to generate the greatest thrust, however if the temperature of the flow entering the combustor is already high, the fuel will only be able to transfer some of the available energy. 


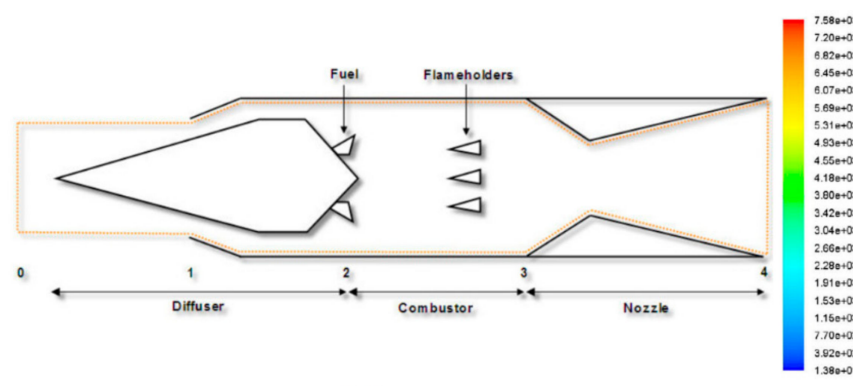

(a)

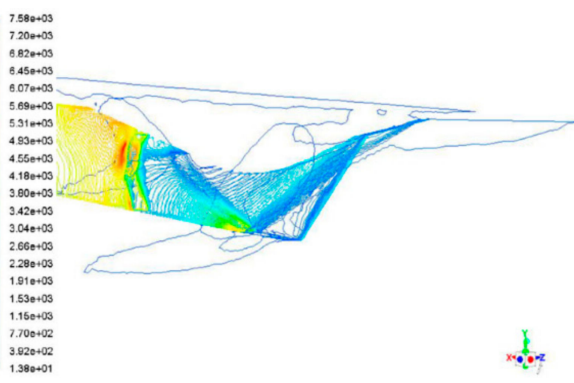

(b)

Figure 16. (a) Flow stations in a ramjet engine and (b) 3D static pressure contours (Pa).

The lack of coherence between results may be a result of assumptions made within the isentropic numerical analysis or perhaps a result of the 3D geometry introducing further losses within the inlet, potentially explaining why losses are magnified at greater Mach numbers. An analysis was performed on the ram drag of the ramjet inlet. The ram drag is calculated via the second term in the equation:

$$
\mathrm{F}=\dot{m}_{4} \mathrm{u}_{4}-\dot{m}_{0} \mathrm{u}_{0}+\left(\mathrm{p}_{4}-\mathrm{p}_{0}\right) \mathrm{A}_{4} .
$$

It is evident that the ram drag $\left(\dot{m}_{0} u_{0}\right)$ reduces the total thrust provided by the engine, and as the flight velocity increases, so does the ram drag. The inlet ram drag calculated in Figure 17 represents both the $2 \mathrm{D}$ and $3 \mathrm{D}$ ram drag values for the given ramjet design.

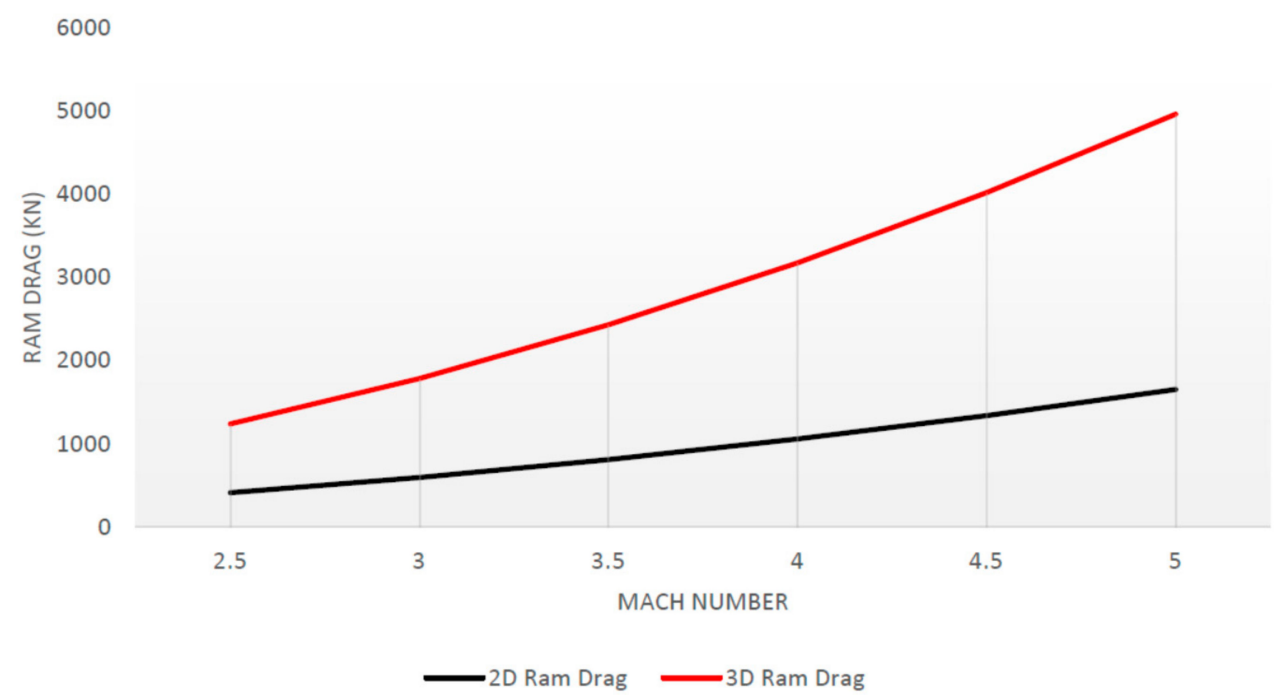

Figure 17. Pressure recovery comparison.

It is important to mention that the ram drag is only a small component of the drag forces that will be experienced; the scramjet inlet's ram drag, along with the drag induced by the entire vehicle, will need to be totalled and taken in to account. The nozzle's propulsive thrust will need to be greater than the sum of all drag components to provide sufficient acceleration.

The 3D ram drag is considerably greater than the 2D ram drag. It was assumed that the ramjet inlet had a width of three meters (further dimensioning can be found in Figure 17 below), allowing another three meters of width for the scramjet inlet. The reason that a total width of six meters was required for engine allocation was due to the engines needing to remain within the extremities of the aircraft's Mach cone. At the position where the engines would be mounted, the vehicle had a wingspan of only six meters, making the decision obvious. This configuration may not necessarily be the width of the final aircraft design and was used to determine the influence. 


\subsection{Data Analysis}

A schematic of the chosen ramjet inlet design is detailed in Figure 18 (providing the ramjet geometry in metres), while Figure 19 shows the influence that the inlet ramps have on the flow at Mach 2.5. Appendix A provides the main geometric properties of the different ramp models. At Ramp 1 , the flow immediately experiences deceleration, along with a decrease in total pressure and increase in static pressure. The second ramp (which is at a greater deflection angle than the first ramp) again decelerates the flow and decreases the total pressure and increases the static pressure. An anomaly occurs between Ramp 3 and the normal shock, where the flow Mach number momentarily increases, along with the total pressure, however there is also a reduction in the static pressure.

This behaviour is not ideal as it increases the amount of deceleration which the flow will experience when passing through the normal shock wave. The reason for the increase in Mach number is because of the small expansion wave which can be seen to form in Figure 2, at the bottom on the inlet lip. Ideally, the design needs further optimisation to reduce the losses associated with the expansion wave.

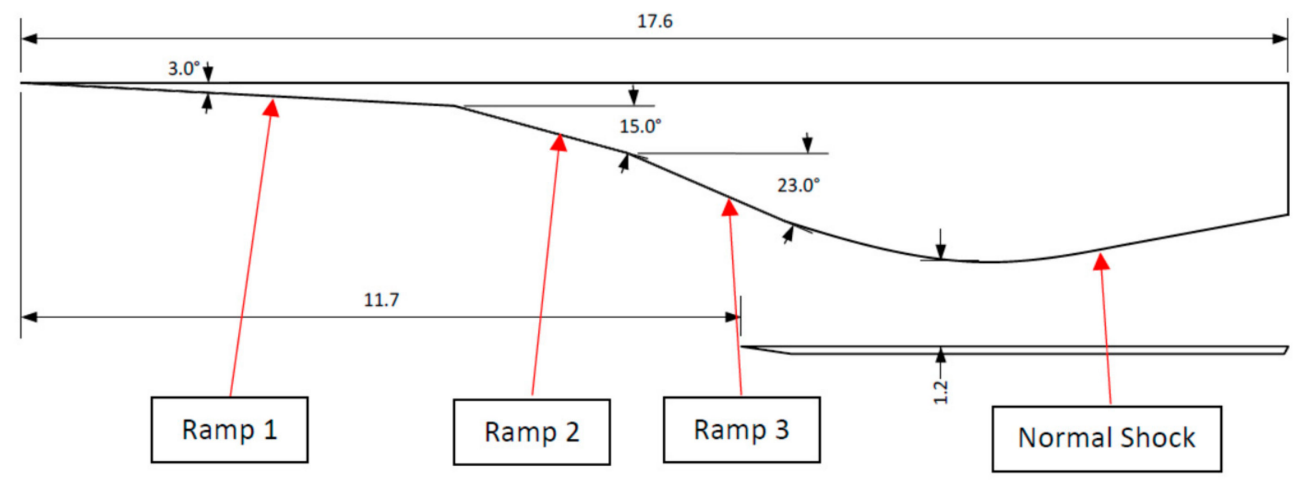

Figure 18. Ramjet inlet schematic.

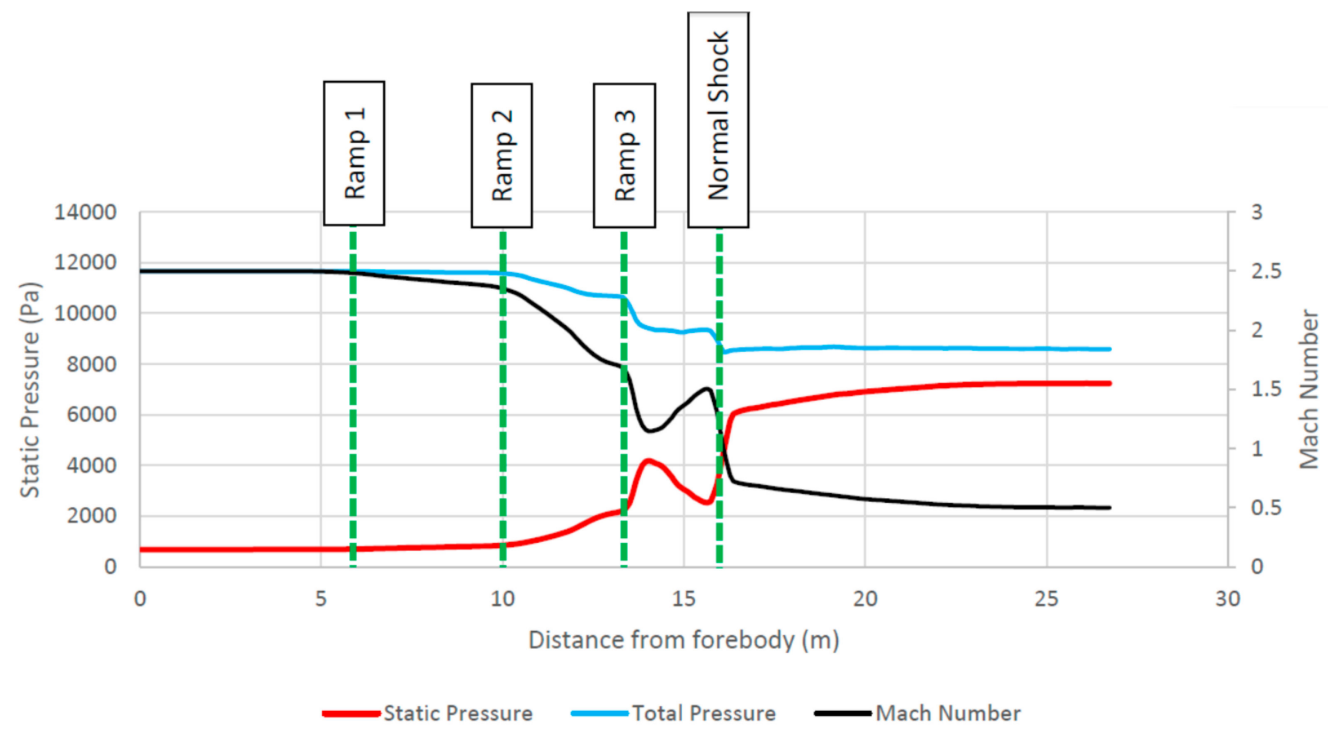

Figure 19. Performance of ramjet inlet at Mach 2.5 (50,000 ft).

Figure 20 shows a similar trend to what was experienced at Mach 2.5, however at a flow Mach number of $M=5$, a lot more losses are present. The first ramp has a minimal influence on the Mach 5 flow, however the influence of Ramp 2 sees a sharp decline in both Mach number and total pressure accompanied by a small rise in static pressure. This trend continues up until the normal shock, where the most drastic changes in flow properties are observed.

Table 2 indicates that as the Mach number increases, the inlet efficiency decreases. This table works to reassure that the loss in pressure recovery is an inherent result of increased free stream 
Mach number. There is potential for more gradual reduction in the Mach number, which would accomplish greater pressure recoveries and better static pressure values, but this would require a more fundamental look at the inlet optimisation problem, which was outside the scope of the present work.

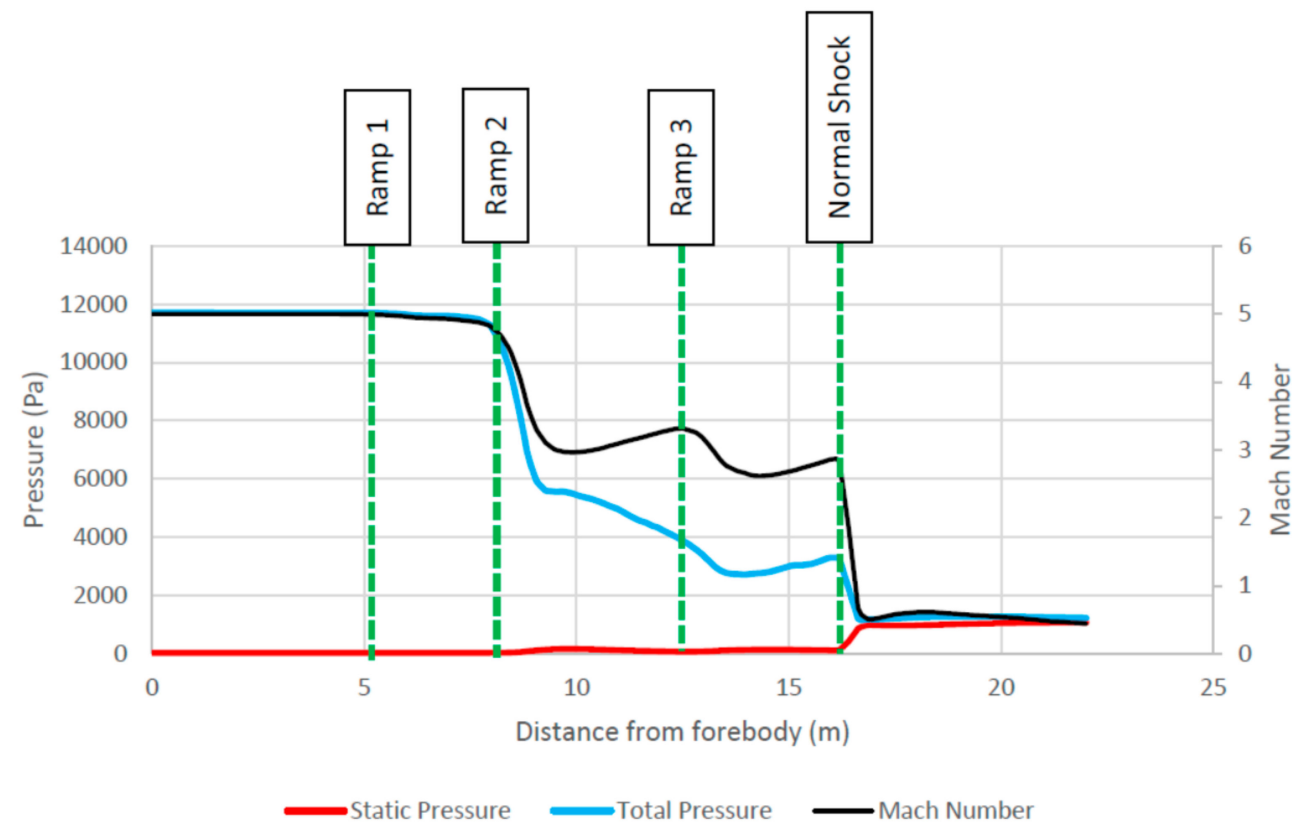

Figure 20. Performance of ramjet inlet at Mach $5.0(50,000 \mathrm{ft})$.

Table 2. Inlet efficiency at different Mach numbers.

\begin{tabular}{cc}
\hline Mach Number & Inlet Efficiency (\%) \\
\hline 2.5 & 87 \\
3 & 80.9 \\
3.5 & 74.2 \\
4 & 66.9 \\
4.5 & 59.3 \\
5 & 51.3 \\
\hline
\end{tabular}

\section{Combined Cycle Ramjet Configuration}

As the vehicle would need to be able to produce thrust when stationary, the ramjet and scramjet would not be suitable for the taxi and take-off aspects of the mission profile. This is where the use of low-bypass turbofan engines will be needed.

Due to the highly aerodynamic shape of the vehicle and the limited amount of space to contain the engines, an over/under configuration was chosen to be used (Figure 21-for illustrative purposes-this figure is not to scale). This configuration allowed for the engines to be stored within the vehicle body (minimising drag) as opposed to the typical subsonic aircraft configuration of external nacelles.

A benefit of the over/under configuration of the ramjet and turbojet engine is that firstly, the physical separation between the ramjet combustion chamber and turbojet assembly allows for higher temperatures within the ramjet to be reached without damaging the turbojet components, contrary to the wrap around configuration. Secondly, as a result of the inlet ramps, a volume has been created behind the ramps which is ideal for the positioning of the turbojet engines. The alternative use could have been for fuel or cargo storage, but as the turbojets are a necessity, it is obvious that they are the option of choice. 


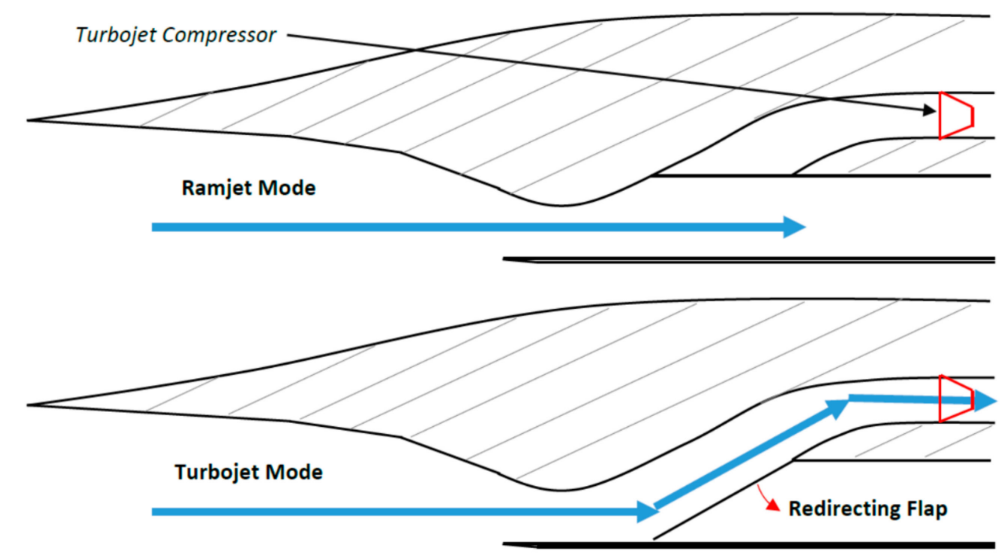

Figure 21. Over/under combined cycle engine investigation.

The turbojet is required to accelerate the vehicle to Mach 2, as the conditions used for CFD analysis assumes Mach 2 conditions. Figure 22 shows that at this velocity, the ramjet inlet still manages to induce a normal shock just aft of the inlet throat. The turbojet requires subsonic flow conditions to achieve efficient performance and minimise shock damage to the compressor blades.

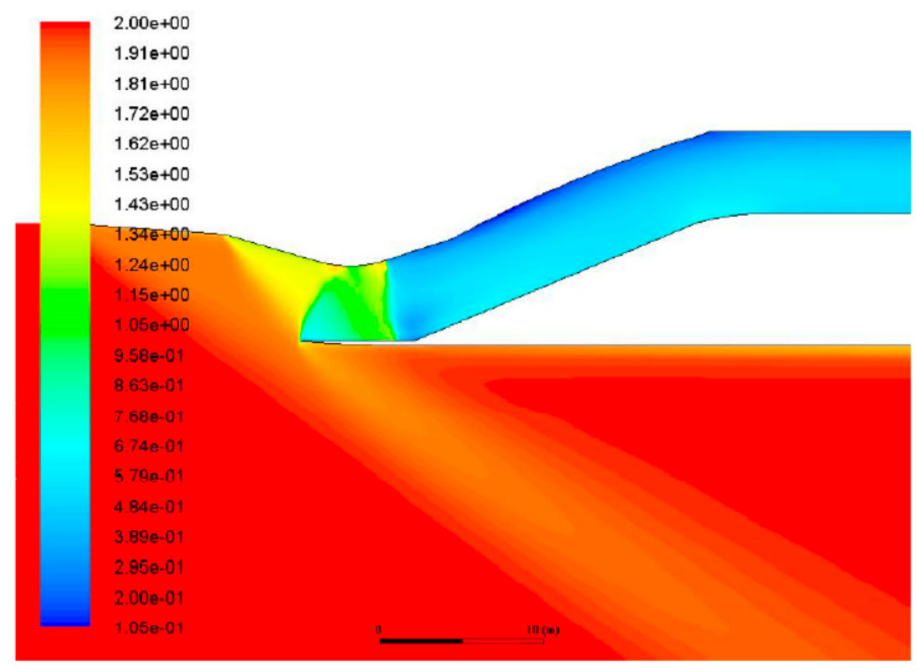

Figure 22. Over/under combined cycle engine Mach contours.

The difficulty at this condition is that without a variable geometry ramp system, the shocks are not ideally aligned with the cowl lip, which will lead to additional drag and minimal shock reflection, ultimately reducing the pressure recovery. The advantage of a turbojet is that its compressors will be able to help overcome pressure issues associated with the losses.

\section{Ramjet-Vehicle Integration}

In addition to the combined cycle configuration of the turbojet and ramjet, the scramjet will also need to be introduced into the final assembly. To achieve the optimal performance from the engines (both ramjet and scramjet), it was essential that the forebody design would cater to both the ramjet and scramjet inlets. Furthermore, due to the different ramp angles etc., a design that introduced minimal interference between the two engines was required. A challenge faced was attempting to minimise the shock formations stemming from the misalignment of the inlet ramps.

In order to provide the required thrust, the inlet area, combustion chamber and nozzle must be adequately sized. In effort to preserve symmetry, the decision was made to place a ramjet on either side of the scramjet as seen in Figure 23. 


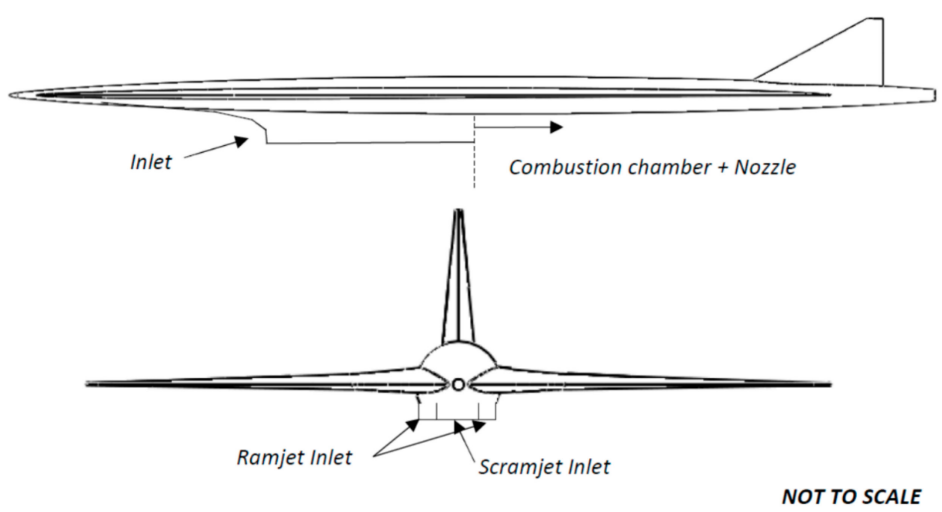

Figure 23. Side and front view of the hypersonic vehicle.

Having the engines located under the vehicle is advantageous in several ways:

1. The vehicle forebody is able to assist in external compression of the oncoming flow [17].

2. Wings remain clean, reducing drag from external engine pylons and nacelles

3. Wings have reduced weight as there is no need for structural support for engines (lower force moments); the reduced structural material leaves room for additional fuel storage

4. The vehicle afterbody can be utilised in the expansion stage of the ramjet and scramjet

The idea of sharing the combustion chamber for both the ramjet and scramjet was explored, however the inherently different geometrical requirements would impose the need of a variable geometry inlet throat and nozzle. The ramjet requires subsonic combustion, mandating a nozzle throat to achieve sufficient expansion. The scramjet, on the other hand, does not experience subsonic combustion, negating the requirement for a throat. Furthermore, it would be a challenge to optimise the combustion chamber to perform effectively throughout the wide range of Mach numbers; for example, the ramjet utilises flame holders, which would cause excessive drag in the case of a scramjet.

The main issues regarding the implementation of the ramjet into the hypersonic vehicle did not arise with the vehicle itself, but with attempting to locate the scramjet and ramjet next to each other with their very different nozzle configurations.

Figure 24 demonstrates the performance of the combined ramjet and scramjet at Mach 5; the black lines signify the ramjet inlet, whereas the red lines indicate the scramjet inlet. The yellow line indicates the location of the normal shock within the ramjet inlet, which can be seen to be just aft of the inlet throat.

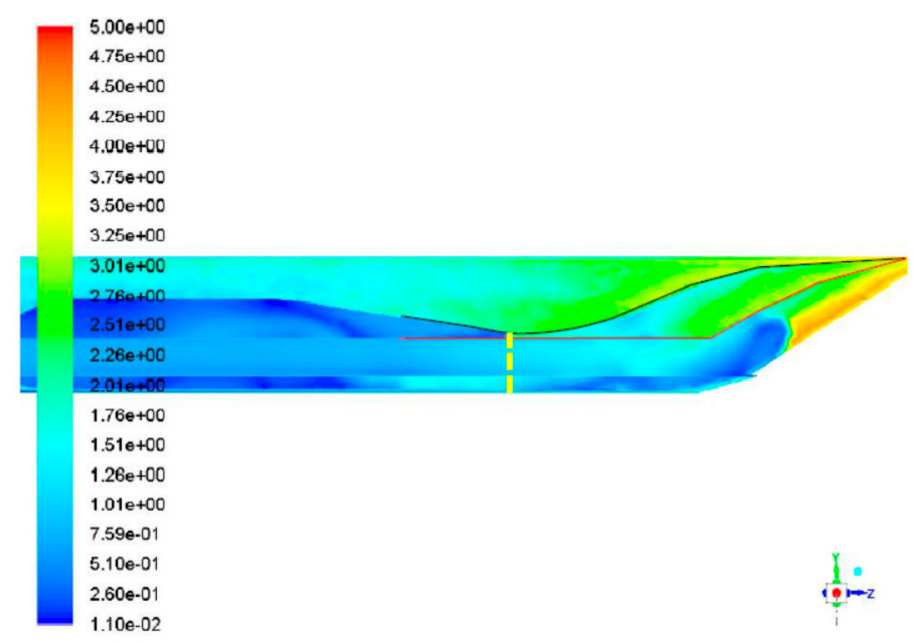

Figure 24. Three-dimensional analysis of the ramjet and scramjet (Mach number). 
It can be seen that there exists an area of subsonic flow just forward of the scramjet inlet, which is not ideal. This is caused by the scramjet choking the flow, creating high levels of spillage and ultimately drag; to mitigate this, the use of a deflection ramp to divert flow away from the scramjet inlet could be implemented while the ramjet is in use.

In addition, the performance of the ramjet has also been affected; this can be seen by the greater variation in flow speed within the combustor inlet. Previous analysis has shown effective flow control throughout the inlet, however the introduction of the scramjet has influenced the shock waves and flow deceleration has become less steady.

This is an adverse effect which may result in an unstable normal shock. The cause of this reduced performance is likely to be a result of the influence of the scramjet's geometry on the formation of shock waves within the ramjet inlet.

Figure 25a provides a front view of the ramjet inlet which was tested using the symmetry line to save on computational demand. A final geometry is represented in Figure 25b, where the two ramjets are located on the outside of the scramjet engine as described in Figure 23.

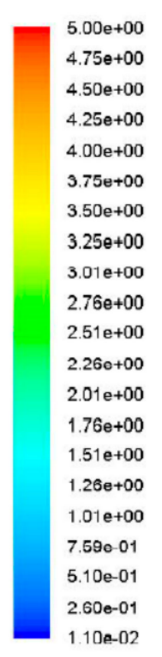

(a)

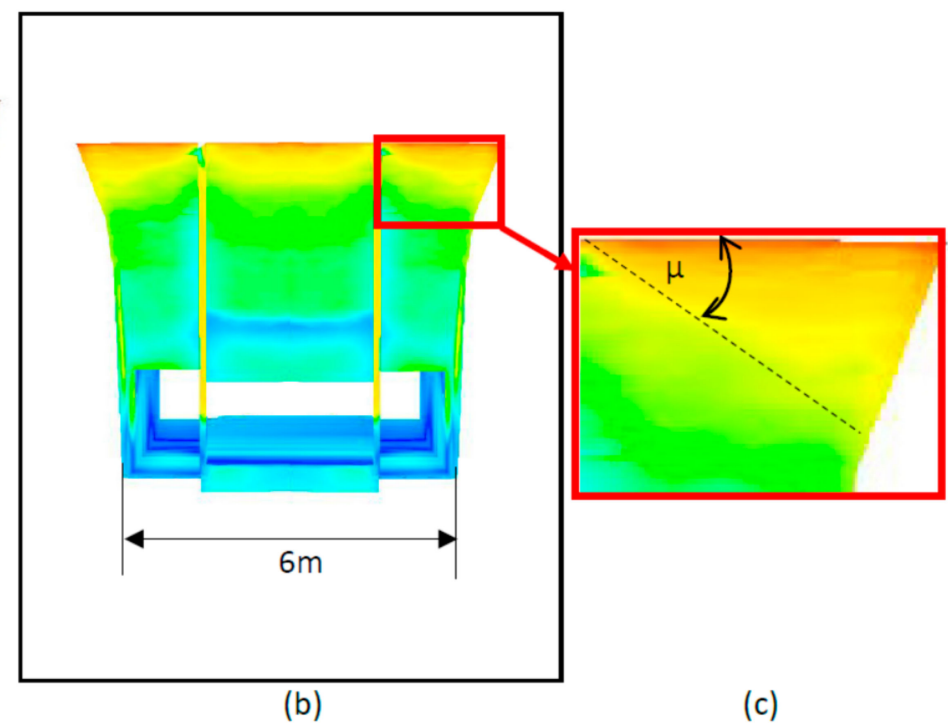

(b) (c)

Figure 25. Ramjet and scramjet $(\mathbf{a}, \mathbf{b})$ full front view with (c) shock angle detail.

Looking at the ramps of the inlets in Figure 25, it is evident where the shock waves are being formed, made visible by the change in colour representing a change in Mach number. Figure 25c shows the influence that the scramjet has on the shocks of the ramjet. The shock waves are being three-dimensionalised, and originate from the walls of the scramjet. Before, when the shocks fell onto the ramjet inlet, they were straight; now, however, they are at an angle due to shock interference.

An additional undesirable characteristic with this configuration is the physical height of the engine inlets required to produce sufficient thrust. A potential configuration which may be able to negate the above issue would be to rotate the two ramjets so that they are essentially mounted sideways, with the first ramp acting as the wall of the scramjet. Rotating the ramjet is likely to see a reduction in the interference of the scramjet on the shock formation leading into the ramjet inlet. A potential issue arises since the ramjet will no longer have a forebody to aid in compression; all compression will need to be performed via the ramp system. Furthermore, the wave-riding effect will be reduced since the momentum change in oncoming flow particles will be deflected outwards as opposed to downward. A potential advantage of this configuration besides for the reduced shock interference is that the hypersonic vehicle may gain directional stability.

Figure 26 shows the alternative design, which is a less tall design allowing for better vehicle integration and a more aerodynamic profile. A cross sectional plan view is shown in Figure 27. 


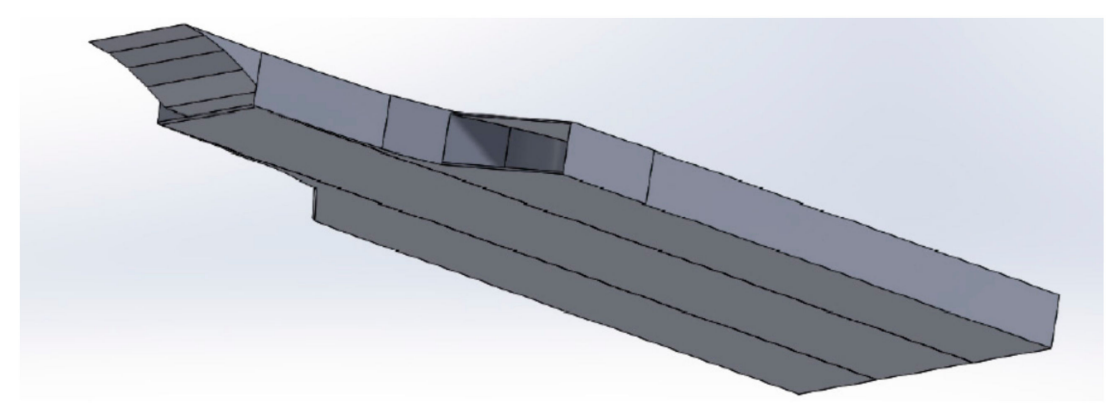

Figure 26. Rotated ramjet configuration.

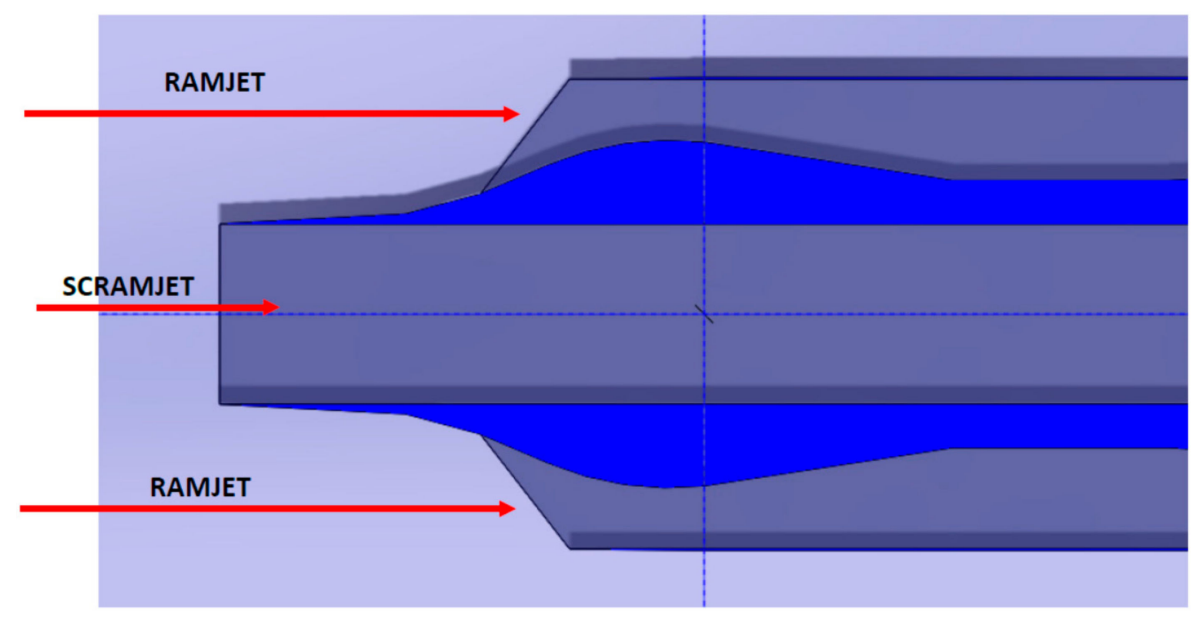

Figure 27. Top view of engine cross section.

Incorporation of this design will impact the design of the over/under configuration required for the implementation of the turbojet engines. A CFD analysis performed on the design shown in Figure 26 confirms that the inlet system for the ramjet is capable at operating throughout the flight profile as seen in Mach 5 conditions in Figure 28. Furthermore, the issue regarding shock interference has been mitigated by altering the configuration.

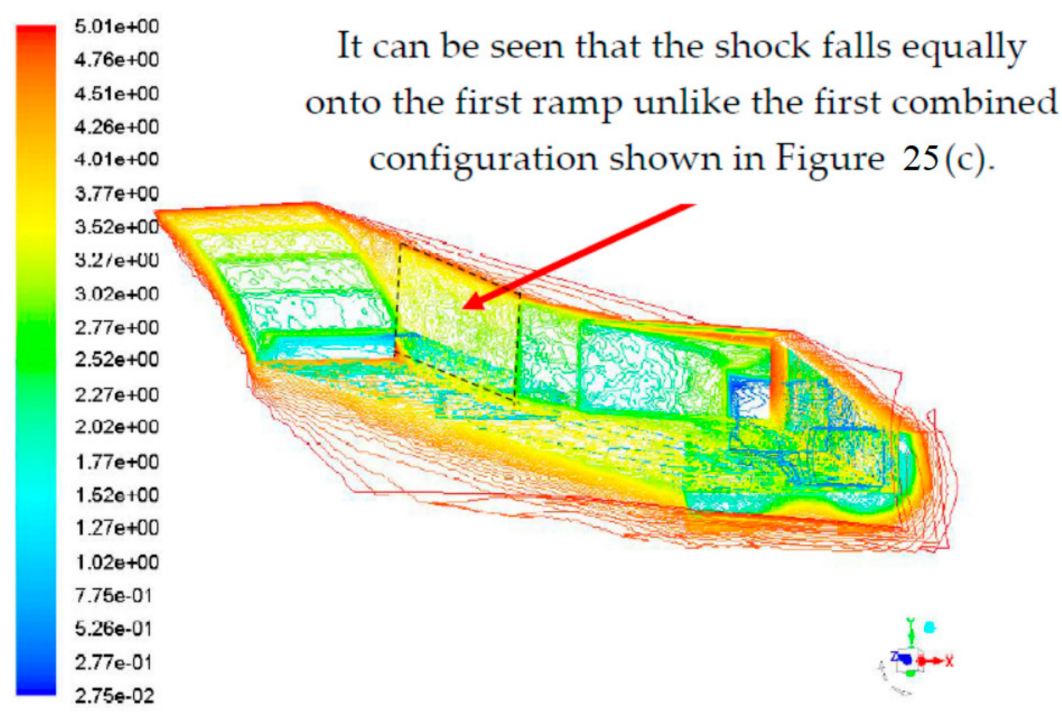

Figure 28. Mach contours for alternative combined cycle engine design. 


\section{Conclusions}

This study set out to analyse the optimum ramjet inlet configuration, which would enable a hypersonic vehicle to perform its mission profile, aiding in acceleration between Mach 2.5 to Mach 5, after which the scramjet engine would engage.

The ramjet must create sufficient thrust at its given operating conditions while also minimising the drag of the vehicle when at hypersonic conditions; this resulted in a compromise in performance characteristics to maintain an aerodynamic shape. Furthermore, as the ramjet is only used for a small fraction of the mission profile, it was decided that for this investigation, a non-variable geometry inlet would be used. The main reason for this is that variable geometry mechanisms increase the weight, especially when needing to tolerate such extreme aero-loading; the additional weight would work to reduce efficiency at high Mach cruise.

The overall performance of the ramjet compression system was seen to become progressively poorer with increasing Mach number, going from roughly $80 \%$ pressure recovery at Mach 2 to $35 \%$ pressure recovery at Mach 5; this could potentially have benefited from a variable geometry inlet. Having said that, the ramjet does achieve subsonic flow conditions within the combustion chamber along with sufficient increases in static pressure and temperature.

Validation through numerical analysis and comparisons with previous literature indicates that the ramjet inlet maintains reliable and consistent results, however the final integration of the entire engine remains questionable due to lack of literature on full ramjet engine performance. Furthermore, the implementation of the ramjet inlet into the rest of the ramjet engine led to challenges including the stabilisation of the back pressure; moreover, introducing combustion into the simulation led to further challenges regarding convergence and reliability of results.

Several configurations of mounting the ramjet inlets adjacent to the scramjet were explored, with the main issues being attributed to the formation of new, interference shock waves. This was overcome by rotating the ramjets $90^{\circ}$ to allow the first ramjet ramp to act as the sidewall for the scramjet. This configuration led to a more uniform formation of shock waves along with a slight reduction in engine weight due to the removal of material from the scramjet wall. The integration of the combined cycle engine configuration into the vehicle itself presented new challenges, including the combination of different CFD models which were used for different reasons throughout individual testing i.e., Spalart-Allmaras vs. k-Omega vs. k-Epsilon. Bringing all the sections together and having to run a design which was optimised using a specific model led to the issue of results varying from what was expected.

In conclusion, the ramjet compression system managed to perform reliably, but would benefit from further optimisation.

Author Contributions: A.P. conceived and designed the experiments and put forward the research concept ideas behind the project; S.V. performed the experiments, analysed the data and wrote the first draft. L.G. contributed to the methodology, technical investigation and supported with the provision of the relevant background theory.

Funding: This research received no external funding.

Conflicts of Interest: The authors declare no conflict of interest.

\section{Appendix A}

\section{Appendix A.1 Mesh Density and Sensitivity Study}

The test conditions were set at Mach 4 with a static pressure at the inlet of $7378 \mathrm{~Pa}$. The main difference between the setup in this report is that this mesh had 190,000 elements compared to the 14.99 million elements used in the aforementioned report (7).

The use of 190,000 elements was justified by the limited computational resources available and mesh convergence study illustrated below in Figure A1, which shows that after 190,000 elements, 
there were no significant changes to the results. The test area was decided to be at a point directly behind the normal shock formed within the inlet throat.

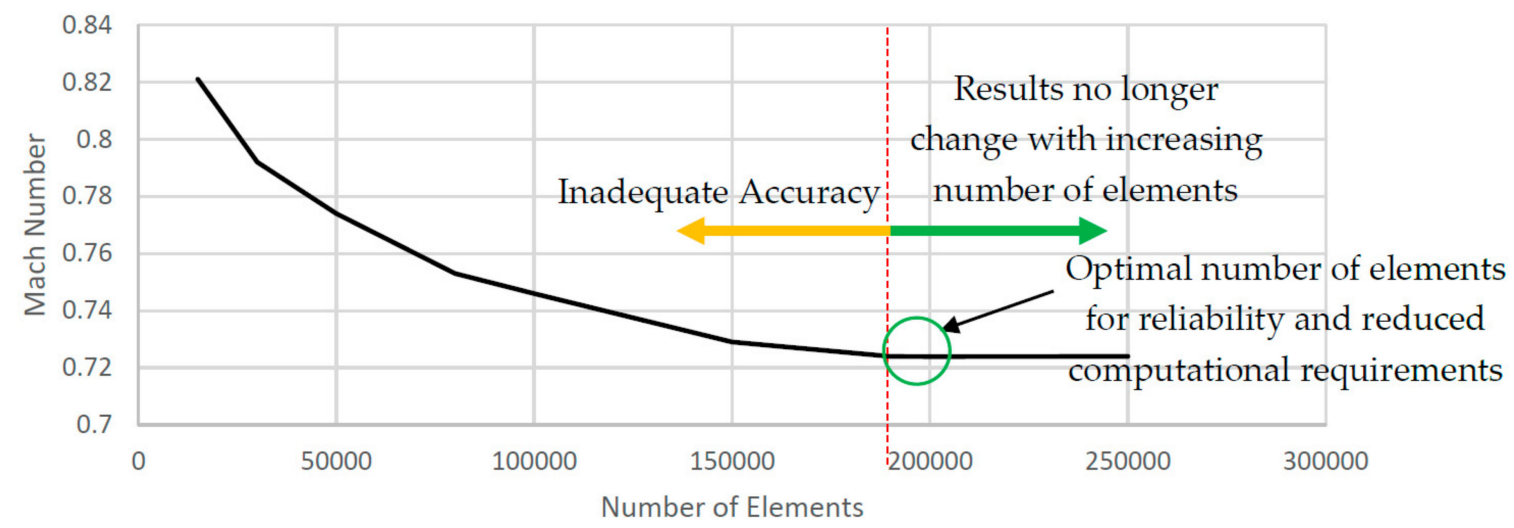

Figure A1. Mach number comparison aft of normal shock.

\section{Appendix A.2 Ramp Configurations}

\section{Appendix A.2.1 Two Ramp Inlet}

Figure A2 displays the schematic of a two ramp external compression system with deflection angles for the first and second ramp of $9^{\circ}$ and $11.5^{\circ}$, respectively. The length of the flat surface underneath the vehicle's forebody and the horizontal length of the ramps was set to $35 \mathrm{~m}$ to allow for the development of the boundary layer. However, the exact distance of the flat surface does not make much of a difference as long as the flow is parallel the horizontal plane.

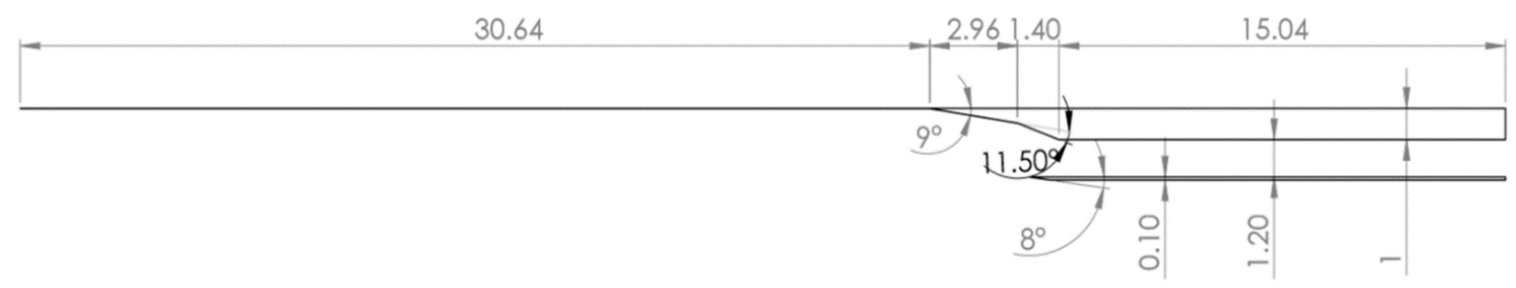

Figure A2. Two ramp inlet schematic (dimensions in metres).

Calculations were carried out to identify the theoretical performance of a scramjet inlet; Table A1 presents some of the important values, such as compression and pressure recovery achieved from the two ramp system. All shock waves are numbered 1 to 5 in the Mach number columns in Tables A1 to A3 below for the increasing numbers of shock waves encountered with two-, three- and four-ramp inlet configurations.

Table A1. Theoretical calculations for two ramp inlet.

\begin{tabular}{cccccc}
\hline $\mathbf{M}_{\mathbf{1}}$ & $\mathbf{M}_{\mathbf{2}}$ & $\mathbf{M}_{\mathbf{3}}$ & Compression Ratio (Prat) & Pressure Recovery (Prec) & Temperature Increase $(\boldsymbol{\phi})$ \\
\hline 4.00 & 3.36 & 2.71 & 5.65 & 0.88 & 1.70 \\
4.50 & 3.74 & 2.99 & 6.73 & 0.84 & 1.81 \\
5.00 & 4.10 & 3.25 & 7.98 & 0.80 & 1.93 \\
\hline
\end{tabular}

Appendix A.2.2 Three Ramp Inlet

Figure A3 depicts the schematic of a three ramp inlet design with deflection angles $\theta 1=9.5^{\circ}$, $\theta 2=9.5^{\circ}$ and $\theta 3=9.5^{\circ}$; having the same deflection angle for all ramps allows for the best pressure recovery. 


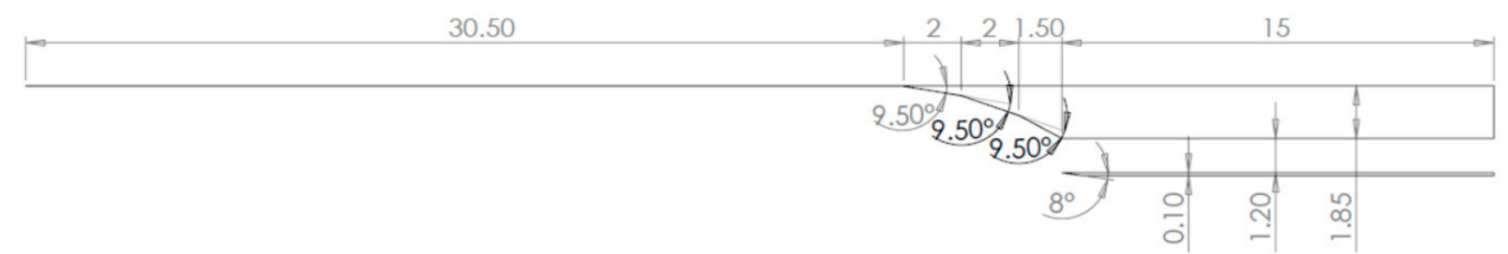

Figure A3. Three ramp inlet schematic (dimensions in metres).

Table A2 presents the theoretical calculations of the Mach number downstream, compression ratio, pressure recovery, static temperature increase and adiabatic efficiency at a range of freestream flow speeds. As it can be seen at Mach 8, the flow should decelerate to Mach 3.788 after passing through the final oblique shock wave, which reaches a compression ratio and pressure recovery of 44.54 and 0.52 , respectively.

Table A2. Theoretical calculations for three ramp inlet.

\begin{tabular}{ccccccc}
\hline $\mathbf{M}_{\mathbf{1}}$ & $\mathbf{M}_{\mathbf{2}}$ & $\mathbf{M}_{\mathbf{3}}$ & $\mathbf{M}_{\mathbf{4}}$ & Compression Ratio (Prat) & Pressure Recovery (Prec) & Temperature Increase $(\boldsymbol{\phi})$ \\
\hline 4.00 & 3.32 & 2.79 & 2.36 & 9.71 & 0.87 & 1.99 \\
4.50 & 3.70 & 3.09 & 2.60 & 12.12 & 0.83 & 2.15 \\
5.00 & 4.05 & 3.36 & 2.82 & 14.94 & 0.79 & 2.31 \\
\hline
\end{tabular}

\section{Appendix A.2.3 Four Ramp Inlet}

Figure A4 exhibits the schematic of a four ramp inlet design with deflection angles $\theta 1=8^{\circ}, \theta 2=$ $8^{\circ}, \theta 3=8^{\circ}$ and $\theta 4=4.5^{\circ}$; these values were selected so as to compare the difference in performance whilst having the same total deflection angle as the three ramped inlet.

Table A3 shows the calculated properties. At Mach 8, the compression ratio achieved is 47.05, the pressure recovery is $62.5 \%$ and the temperature increase ratio is 3.489 . The compression ratio and stagnation pressure recovery achieved is better than the three ramp inlet with the total deflection (three ramp inlet has Prat $=44.54$ and Prec $=52 \%$ ).

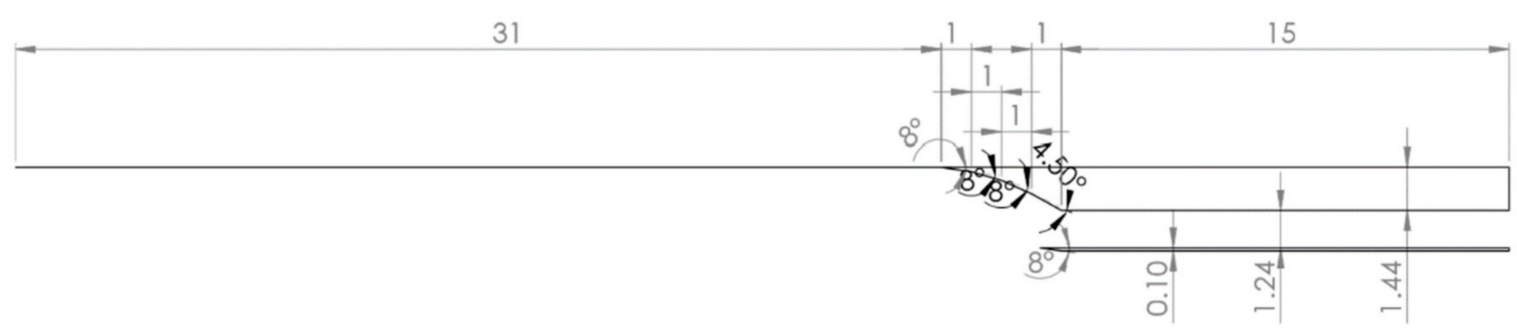

Figure A4. Four ramp inlet schematic (dimensions in metres).

Table A3. Theoretical calculations for four ramp inlet.

\begin{tabular}{cccccccc}
\hline $\mathbf{M}_{\mathbf{1}}$ & $\mathbf{M}_{\mathbf{2}}$ & $\mathbf{M}_{\mathbf{3}}$ & $\mathbf{M}_{\mathbf{4}}$ & $\mathbf{M}_{\mathbf{5}}$ & Compression Ratio (Prat) & Pressure Recovery (Prec) & Temperature Increase $(\boldsymbol{\phi})$ \\
\hline 4.00 & 3.43 & 2.96 & 2.57 & 2.43 & 9.79 & 0.91 & 1.97 \\
4.50 & 3.82 & 3.28 & 2.84 & 2.69 & 12.24 & 0.88 & 2.12 \\
5.00 & 4.2 & 3.58 & 3.09 & 2.93 & 15.22 & 0.85 & 2.33 \\
\hline
\end{tabular}

\section{References}

1. McClinton, C.R. X-43-Scramjet Power Breaks the Hypersonic Barrier. In Proceedings of the 44th AIAA Aerospace Sciences Meeting and Exhibit, Reno, Nevada, 9-12 January 2006.

2. Berry, S.; Daryabeigi, K.; Wurster, K. Boundary-Layer Transition on X-43A. J. Spacecr. Rocket. 2010, 47, 922-934. [CrossRef] 
3. Sziroczak, D.; Smith, H. A review of design issues specific to hypersonic flight vehicles. Prog. Aerosp. Sci. 2016, 84, 1-28. [CrossRef]

4. Fry, R.S. A Century of Ramjet Propulsion Technology Evolution. J. Propuls. Power 2004, 20, 27-58. [CrossRef]

5. Curran, E.T. Scramjet Engines: The First Forty Years. J. Propuls. Power 2001, 17, 1138-1148. [CrossRef]

6. Baidya, R.; Pesyridis, A.; Cooper, M. Ramjet Nozzle Analysis for Transport Aircraft Configuration for Sustained Hypersonic Flight. Appl. Sci. 2018, 8, 574. [CrossRef]

7. Neill, S.M.; Pesyridis, A. Modeling of Supersonic Combustion Systems for Sustained Hypersonic Flight. Energies 2017, 10, 1900. [CrossRef]

8. Sen, D.; Pesyridis, A.; Lenton, A. A Scramjet Compression System for Hypersonic Air Transportation Vehicle Combined Cycle Engines. Energies 2018, 11, 1568. [CrossRef]

9. Chen, B. Numerical Performance Prediction of a Miniature Ramjet at Mach. 4; Naval Postgraduate School: Monterey, CA, USA, 2012.

10. ANSYS. Inputs at Pressure Far-Field Boundaries; ANSYS Help: Canonsburg, PA, USA, 2009; p. 7.3.10.

11. Bonelli, F.; Cutrone, L.; Votta, R.; Viggiano, A.; Magi, V. Preliminary design of a hypersonic air-breathing vehicle. In Proceedings of the 17th AIAA International Space Planes and Hypersonic Systems and Technologies Conference, San Francisco, CA, USA, 11-14 April 2011. [CrossRef]

12. Bonelli, F.; Tuttafesta, M.; Colonna, G.; Cutrone, L.; Pascazio, G. An MPI-CUDA approach for hypersonic flows with detailed state-to-state air kinetics using a GPU cluster. Comput. Phys. Commun. 2017, 219, 178-195. [CrossRef]

13. O’Briant, S.A.; Gupta, S.B.; Vasu, S.S. Review: Laser Ignition for Aerospace Propulsion. Propuls. Power Res. 2016, 5, 1-21. [CrossRef]

14. Beeker, G.L.; Bennett, R.L.; Payne, J.M. Aero Propulsion-Performance Flight Testing, Edwards AFB, CA. 1991. Available online: http:/ / scholar.google.com/scholar?hl=en\&btnG=Search\&q=intitle:Performance+ Flight+Testing\#0 (accessed on 1 July 2018).

15. Harloff, G.J.; Smith, G.E. Supersonic-inlet boundary-layer bleed flow. AIAA J. 1996, 34, 778-785. [CrossRef]

16. Nguyen, T.; Reinartz, B.; Behr, M.; Hohn, O.; Gülhan, A. Numerical Investigations of the Effects of Sidewall Compression and Relaminarization in 3D Scramjet Inlet. In Proceedings of the AIAA International Space Planes and Hypersonic Systems and Technologies Conference, San Francisco, CA, USA, 11-14 April 2011. [CrossRef]

17. Jones, R.A.; Huber, P.W. Airframe-Integrated Propulsion for Hypersonic Cruise Vehicles. In Proceedings of the 11th International Council of the Aeronautical Sciences, Lisbon, Portugal, 10-16 September 1978. 